\title{
Immigrant Locations and Native Residential Preferences: Emerging Ghettos or New Communities?*
}

\author{
Jesús Fernández-Huertas Moraga ${ }^{\mathrm{a}}$, Ada Ferrer-i-Carbonell ${ }^{\mathrm{b}}$, and Albert Saiz ${ }^{\mathrm{c}}$ \\ ${ }^{a}$ Universidad Carlos III de Madrid ${ }^{\dagger}$ \\ ${ }^{\mathrm{b}} I A E, C S I C$, and Barcelona GSE \\ ${ }^{\mathrm{c}}$ Massachusetts Institute of Technology ${ }^{\S}$
}

December 5, 2018

\begin{abstract}
While the impact of immigrants on labor markets may be small, strong political movements voicing opposition to the growth of resident foreign-born populations are on the upswing. We study whether natives voted with their feet in reaction to the largest and fastest migration shock in the OECD. The inflow-causing the population of Spain to grow by 10 percent between 1998 and 2008-represented largely a new phenomenon, the size of which had not been factored into previous expectations, thereby providing quasi-experimental sources of variance. Our results show that immigrant inflows caused mild native displacement from denser, established neighborhoods, but also more real estate development there. In parallel, both natives and immigrants were collocating in new booming suburban communities, resulting in no changes to overall measures of ethnic segregation. In contexts where large ethnic-minority arrivals spur the creation of new neighborhoods, conventional empirical methods may overstate the degree of ethnic displacement.
\end{abstract}

Keywords: international migration; residential segregation; native flight.

JEL classification codes: F22, J61, D33.

\footnotetext{
*We are grateful to Simone Bertoli, Amparo González, Joan Monràs, Rosella Nicolini and Francesc Ortega for their comments and suggestions. We also thank seminar participants at the Universidad de Alicante, IREA-UB Institute (Universitat de Barcelona), IEB (Universitat de Barcelona), the Department of Applied Economics (Universitat Autònoma de Barcelona), CERDI (Université d'Auvergne), IRES (Université Catholique de Louvain), IZA, UC Riverside, Williams College, Trinity College Dublin, University of British Columbia, Ruhr Graduate School of Economics, the $7^{\text {th }}$ INSIDE Workshop at the Barcelona GSE Summer Forum, the $4^{\text {th }}$ CEPII-OECD Conference on "Immigration to OECD Countries" in Paris and the CEMIR Junior Economist Workshop on Migration Research in Munich. We also wish to thank Lídia Brun for her excellent work of data collection and Blake Willmarth and Erdal Karahan for their research assistance. We acknowledge the financial support received by the RecerCaixa grant. Jesús Fernández-Huertas Moraga gratefully acknowledges the support from the Ministerio de Economía, Industria y Competitividad (Spain), grants ECO2016-76402-R and MDM 2014-0431, and from the Comunidad de Madrid, MadEco-CM (S2015/HUM-3444). The usual disclaimers apply.

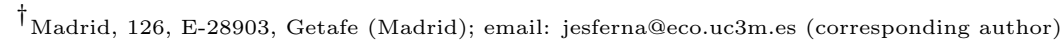

${ }^{\ddagger}$ Campus UAB, 08193 Bellaterra (Barcelona), Spain; email: ada.ferrer@iae.csic.es

$\S$ Department of Urban Studies and Planning; 77 Massachusetts Avenue, Cambridge, MA 02138, USA; email: saiz@mit.edu
} 


\section{Introduction}

International migration has become one of the central political issues of our time. The population share of the foreign-born in high-income OECD countries increased by approximately 1 percentage point every five years between 1990 and 2010: from 7 percent to 11 percent (World Bank, 2013). This has led economists to investigate how immigrants affect destination economies. Most studies - focusing on labor markets - arguably show that wage impacts on natives are relatively small. ${ }^{1}$

Nevertheless, attitudes towards immigration depend on other issues, such as its impact on welfare benefits or ethnic identities (Dustmann and Preston, 2007). Some researchers, like Borjas (2013) or Saiz and Wachter (2011), claim that the largest impacts of immigration may not be found in the labor market but rather in other interaction spaces between natives and immigrants. After all, robotization, capital deepening, Information Technologies, Artificial Intelligence, trade, global outsourcing, and off-shoring, have also profound impacts on employment, wages, and the labor market. Yet they do not seem to galvanize opinion in the same way as immigration. This suggests that the residential aspects of this phenomenon are perceived as critically important by natives. In this context, we need to study where immigrants settle, and how their settlement decisions affect natives as revealed by residential choices.

To this end, we focus on one of the world's largest and swiftest immigration experiences. In only ten years, between 1998 and 2008, the immigrant population share in Spain increased from 3 percent to a staggering 13 percent. We perform a comprehensive study of natives' residential responses, combining microdata on exact addresses of the resident population with distance to amenities and socioeconomic characteristics by neighborhood. Building on Saiz and Wachter (2011) and Kasy (2015), we also construct instrumental variables (IV) based on the geographic diffusion of immigrant inflows to estimate the causal impact of the latter on natives' outflows.

In an environment of massive, ex novo inflows, we find that: (i) immigrants mildly displaced natives from city centers and dense suburban areas: one native leaving for every three immigrants moving in; and (ii) residential construction also increased in established

\footnotetext{
${ }^{1}$ See Docquier, Ozden, and Peri (2014), for example. Some authors argue that the distributional consequences for particular groups can be very large (Borjas and Monras, 2017) although others disagree (Clemens and Hunt, 2017).
} 
neighborhoods with more immigrant arrivals. We argue that these facts are inconsistent with the existence of strong native discriminatory residential behavior. We also show that: (iii) new housing developments in suburban areas saw proportional collocation of immigrants and natives; and (iv) the resulting effect on average immigrant segregation was neutral. The results point to dynamics that are not always captured by conventional tipping and segregation models, which assume a fixed number of neighborhoods, often ignoring the role of new real estate development.

Most recent literature on the effect of ethnic displacement has centered on the US, e.g. Cutler, Glaeser, and Vigdor (2008); Card, Mas, and Rothstein (2008); Saiz and Wachter (2011), where migrant inflows into cities have been progressive and continuous. The richness of our original dataset is similar to that in Scandinavian studies. Denmark and Sweden have been very gradual net recipients of migrant flows and studied by Edin, Fredriksson, and Åslund (2003) or Damm (2009). In parallel to our research, Andersson, Berg, and Dahlberg (2018) study the process of native flight from neighborhoods that received refugee settlement in Sweden, finding that each immigrant displaced 0.3 natives on average. ${ }^{2}$

There is a number of papers dealing with the measurement of residential segregation in Spain, but none of them analyzes the causal reaction of natives to localized immigrant arrivals. ${ }^{3}$ In contrast to most of the previous literature, our geocoded data allow us to study the phenomenon in a context where its magnitude and speed were very sizable and unpredicted. Furthermore, we have very detailed micro data on immigrant and native locations, and a much broader coverage of the neighborhood characteristics that could have impacted native mobility even in the absence of migratory flows. Therefore, our results are less likely to be plagued by omitted variables' bias.

\footnotetext{
${ }^{2}$ Other work focuses on the UK (Giulietti, 2009; Bell and Machin, 2013; Hatton and Tani, 2005), Italy (Boeri, Philippis, Patacchini, and Pellizzari, 2015; Brücker, Fachin, and Venturini, 2011; Accetturo, Manaresi, Mocetti, and Olivieri, 2014), the Netherlands (Gautier, Siegmann, and Van Vuuren, 2009), or France (Verdugo, 2011).

${ }^{3}$ For example, Pareja-Eastaway (2009) and García-López (2012) measure segregation in Barcelona, while Blázquez, Llano, and Moral (2010) relate commuting times to segregation (1996-2004), and Echazarra (2010) studies the correlates of neighborhood segregation (2001-2006) in Madrid. Bosch, Carnero, and Farré (2010) study the existence of ethnic discrimination against immigrants in the rental market. Ballester and Vorsatz (2014) produce cross-sectional segregation measures. Without focusing on immigrants, De la Roca and Puga (2017) and De la Roca (2017) study the sorting of individuals by skills and city size. Finally, Maza, Villaverde, and Hierro (2013) look at the determinants of immigrants' locations across Spanish provinces.
} 
The immigration wave in Spain coincided with the housing boom (Nicodemo and Raya, 2012), we suspect not coincidentally. González and Ortega (2013) use inter-regional variation to find that 'immigration was responsible for one quarter of the increase in prices and about half of the construction activity over the decade' (2000-2010). We focus on neighborhoodlevel variation, where comprehensive data on prices during that period do not exist. Our estimates of the effect of immigrant arrivals on native mobility are therefore reduced-form, comprising both: (i) native preferences for neighborhood ethnic composition; and (ii) equilibrium effects by the way of housing prices and native price elasticities of substitution between neighborhoods. Nevertheless, we do exploit data on residential housing construction, which turns to be a critical issue. Studies in the ethnic segregation literature that abstract from housing supply effects - for instance by chiefly focusing on changes in racial shares - may therefore be lacking. We argue that, in rapidly growing cities, we need to study relative demographic inflows and new housing construction concurrently.

The next section describes and benchmarks the immigration boom. In section 3, we detail the construction of our database, sketch our methodology, and show summary statistics. Section 4 presents our main empirical estimates and relates them to the emergence of new metropolitan suburbs. Section 5 concludes by discussing how the findings may shed light on the current literature on white/native flight and segregation.

\section{Largest Immigration Boom in Recent History}

Spain's experience in the early 2000s offers a unique opportunity to study a quasi-exogenous, unexpected, and economically-meaningful immigrant shock. Figure 1 compares the evolution of its foreign-born share versus other OECD countries'. Starting at 2.1 percent in 1990, it had reached 13.8 percent by 2010, making this into one of the largest episodes on record. ${ }^{4}$ Looking at absolute numbers (Table 1), only the United States had received more immigrants (19.6 million versus 5.5 million); and the third ranking country was Germany, with 4.8 million, both smaller inflows relative to their populations.

(Figure 1) (Table 1)

\footnotetext{
${ }^{4}$ Friedberg (2001) also exploits a massive inflow in Israel. Cambodia's share raised from 0.4 to 2.4 and is second in the world with a 490 percent increase. The closest experiences among developed countries are Finland (232 percent increase, from 1.3 to 4.2), Iceland (211 percent increase, from 3.8 to 11.7) and Ireland (210 percent increase, from 6.5 to 20). Own calculations from World Bank (2013).
} 
Figure 2 shows the share of immigrants by province in 2001 and 2008. While immigrant concentration increased substantially in all provinces, Madrid, the Canary Islands, and the Mediterranean accounted for three quarters of the inflows (compared to their 53.3 percent share of the native population).

(Figure 2)

The country's 83 metropolitan areas - as defined by the Ministry of Housing (Ministerio de Vivienda, 2007) - received 72.7 percent of the foreign population inflows, compared to their 66.9 percent share of the native population. Administratively, these 83 metropolitan areas comprise 744 municipalities, on which we focus in this work; the remaining 7,368 municipalities are small, only 70 of them having more than 25,000 inhabitants.

The composition of the metro immigrant population also changed, with Latin American countries - mainly Ecuador, Colombia and Argentina-becoming the main origins (46.5 percent of new arrivals). Another growing area of origin was Eastern Europe, mostly Romania, which consolidated a 22.7 percent of the immigrant intake. 8.7 percent arrived from the Maghreb, chiefly Morocco. Other smaller inflows were from developing countries in Asia (China, Pakistan, Philippines, and India), and Subsaharan Africa. Inflows contrast to the situation in 1998, where 47.7 percent of the foreign-born had hailed from most-developed countries (mainly UK and Germany). This marked change in the composition of immigrant origins provide strength to the use of our Card-like instruments (Card, 2001) to establish causality (Jaeger, Ruist, and Stuhler, 2018).

Following Massey and Denton (1988), we start by calculating dissimilarity and isolation indexes, both measuring the segregation of our target populations. As in Cutler, Glaeser, and Vigdor (2008), we define minority groups by country of birth. Neighborhoods are defined as each of 21,505 metropolitan censal sections in 2008 - an administrative division used for electoral purposes - which we refer to as census tracts hereinafter. With some exceptions, census tracts were designed to hold between 500 and 2,500 inhabitants. Figure 3 shows the population-weighted average of national isolation indexes across foreign groups. For comparison, the same indexes - as calculated by Cutler, Glaeser, and Vigdor (2008) - are shown at the same scale. The average dissimilarity coefficient slightly decreased to around a value of 0.45 , while the mean isolation index very slightly increased. This situates the dissimilarity-based segregation of immigrants at the same levels as US immigrants in the 1970s, and their isolation lower than the minimum ever attained in the US (slightly below 
0.04 in 1950).

(Figure 3)

Overall segregation indexes hide a vast range of experiences by metro area and nationality (Fernández-Huertas Moraga, Ferrer, and Saiz, 2011), but their evolution is robust to different neighborhood definitions, groupings of nationalities, or to using more sophisticated segregation indexes (Ballester and Vorsatz, 2014). Such results are surprising: immigrants from developing countries may have been perceived as possessing low socioeconomic status (SES). According to Amuedo-Dorantes and De la Rica (2007) the percentages of working age immigrants from developing countries who were dropouts, had completed some secondary education or completed college education was 36, 52 and 12 percent respectively. This compares to 26,58 and 16 percent respectively for working-age natives. Some commentators argued that the educational differences between natives and immigrants were thus relatively small. However, Spain had been a developing country itself throughout the 50s, 60s, and 70s. This meant that the accumulated stock of human capital had been very low among older workers. According to OECD (2009), if we look at the native population aged between 25 and 34 in 2007, the percentage of college graduates was at a much higher 39 percent, more than 3 times the share among immigrants. Therefore the flow of immigrants represented a lower-educated pool compared to the flow of natives entering the Spanish labor market concurrently. Furthermore, even highly-credentialed immigrants were taking low-paying, mostly manual, jobs. Rodríguez-Planas and Nollenberger (2016) describe how "At arrival, low-skilled migrants earn 27 percent lower wages than similar natives, while medium- and high-skilled migrants earn 36 and 47 percent lower wages than their native counterparts. Moreover, estimates $[\ldots]$ also reveal that the immigrant wage penalty only decreases over time for low-skilled migrants." Therefore, even when possessing similar theoretical credentials, college-educated immigrants were much poorer than natives. Due to the large nature of the inflows, immigration was perceived as a major social issue among the autochthonous population. 48 percent of respondents to the government's sociological survey in 2008 deemed the level of immigration "excessive," and a further 31 percent thought it was "high," with only 19 percent thinking that immigration levels were "acceptable" (Cea D'ancona and Valles Martínez, 2014). What were then the mechanisms that combined into relatively uneventful aggregate results in the residential market? 


\section{Methodology}

\subsection{Data and Geographies}

During most of this period, starting in January 1998, the national statistics office (INE, Instituto Nacional de Estadística) gathered information about the location of every person in the country through the "Padrón Municipal de Habitantes" (INE, 2009). The Padrón is the official registry of population by municipality. ${ }^{5}$ Individuals have strong incentives to register upon moving, as registration is required to enjoy public services in proximity to their residence, such as education and health. All newborn children are immediately registered before discharge, and deceased persons are removed upon death certification.

Immigrants faced additional incentives to register as soon as they settled. Registration had been used to prove residency in the periodical regularizations since the Law 4/2000. Hundreds of thousands of immigrants took advantage of being duly registered in the 2000, 2001 and 2005 amnesties. Also, the Law 4/2000 specifically provided access to all public services to immigrants who registered, including the undocumented. Table 1 shows the evolution of the total population, the foreign-born, and their share between 1998 and 2008 according to the Padrón. Population increased by 16 percent, with immigration being directly responsible for 77 percent of such growth. ${ }^{6}$

We obtained access to individual micro-data from the official registry during the immigration boom. We have the ability to determine the location and some characteristics of all the approximately 45 million residents each year. Data include the exact address of every registered individual living in the country between 1999 and 2008, their gender, date and place of birth (municipality for natives, country of birth for immigrants), education level (only up to high school), and nationality. Having the exact localization of each individualwhich we geocoded at each unique address - allows us to circumvent any problems generated

\footnotetext{
${ }^{5}$ Local public funding levels are determined by this official measurement of population. Hence municipalities may have incentives to inflate these numbers while the central government has the opposite ones. Overall, Fernández-Huertas Moraga, Ferrer, and Saiz (2011) estimate that the Padrón inflated the actual population numbers by only about 2 percent in 2001 .

${ }^{6}$ Padrón figures are not completely reliable for immigrants until 2001, as documented by Bertoli and Fernández-Huertas Moraga (2013). Before the Law 4/2000, municipalities could use some discretion regarding the registration of immigrants, particularly if they were undocumented. This means that some of the registrations in 2001 correspond to earlier arrivals, likely from the two previous years. To avoid measurement error in the exact timing of registration we use long differences (2001-2008).
} 
by changes in administrative neighborhood definitions. The data, however, do not contain household identifiers or individual IDs .

We complement this unique dataset with socioeconomic variables at the tract level from the 2001 census (INE, 2005), to which we matched each of the about 7 million unique registry addresses. We also use ESRI StreetMap Premium Europe NAVTEQ 2009 Release 2 (ESRI, 2009) to calculate the distance of each address to a series of 62 different points of interest (POIs). ${ }^{7}$ We then construct gravity measures: the sum of all POIs in the province weighted by the inverse of their square distance.

A substantial portion of demographic change in growing cities naturally occurs in areas that had been scarcely populated earlier, but which see new residential development concurrently with migrant arrivals. Administrative boundaries lump together these newlydeveloped areas with existing, denser settlements. In addition, government-defined neighborhoods are formalized ex post in ways likely to be endogenous to the phenomena of interest. Therefore, as in Shertzer and Walsh (2016), we generate and use exogenously-defined geographic units. In our case, we divide the whole country into squares of width and height equal to 0.005 longitude and latitude degrees. At the average latitude, our squares have an approximate width of 555 meters. The average population of the 28,523 metropolitan squares was of 1,074 (s.d. $=2,127$ ). ${ }^{8}$ Because segregation patterns could be sensitive to geographical aggregation (Logan, Zhang, Turner, and Shertzer, 2015), we also use larger quadrants of 0.1-degree side length and show results to be robust.

Table 2 summarizes our control variables by source and year of measurement. When possible, variables are measured at baseline - 2001 - corresponding to that census year. However, our POI gravities (Table 2) are measured in 2008 as detailed data from navigation systems were relatively rare earlier on (ESRI, 2009).

(Table 2)

To realize the importance of new neighborhoods, note that 7 percent of the squares in

\footnotetext{
${ }^{7}$ See Table 2 for a full itemization

${ }^{8}$ The average population by census tract was 1,452 (s.d.=575). While the physical area of our neighborhoods is not exactly constant across latitudes, it is very close to being so. Note that census tracts are substantially more irregular in shape than our random boundaries, in addition to their endogeneity. Using constant latitude and longitude sizes makes the neighborhood assignment process for the more than 7 million unique addresses computationally feasible. Note further that metropolitan fixed effects take care of the very small area differences across cities at different latitudes.
} 
the country's metro grid were empty in 2001 but had become inhabited in 2008 by 234,000 natives and 45,000 immigrants (almost half of them in metro Madrid). In addition, an extra 19 percent of neighborhoods more than doubled their size, going on to encompass 6 percent of the metro population in 2008 (1.5 million people). These sprouting neighborhoods were an extreme consequence of the construction boom.

\subsection{Natives and Immigrants: Outflow-Inflow}

Consider a neighborhood $k$, in metropolitan area $m$, at time period $t$, and the following naive single-equation model:

$$
\Delta \operatorname{nat}_{k, m, t}=\theta_{m, t}+\beta \triangle i m_{k, m, t}+X_{k, m, t-1}^{\prime} \Gamma+\gamma_{n} S_{k, m, t}+\varepsilon_{k, m, t}
$$

Changes in native population between $t$ and $t-1$ are a function of: a metropolitan shifter $\left(\theta_{m, t}\right)$; the number of net immigrant arrivals $\left(\triangle i m_{k, m, t}\right)$; initial neighborhood characteristics - the valuation of which may be changing $\left(X_{k, m, t-1}\right)$; an additional shock due to changes in employment or amenities $\left(S_{k, m, t}\right)$; and an i.i.d. random component $\left(\varepsilon_{k, m, t}\right)$. In order to compare neighborhoods, demographic flows may be scaled to initial population. ${ }^{9}$

The parameter of interest in equation (1) is $\beta$, which corresponds to the net native population loss or gain associated with the arrival of one immigrant. We hereinafter denominate it the average outflow-inflow coefficient. $\beta$ is a reduced-form parameter. It arises from a general-equilibrium process involving the residential tastes of the different ethnic groups. Because there is a large number of neighborhoods in each metropolitan area, housing prices capture compensating differentials across them. Changes in the local ethnic composition may repel (attract) natives. But the subsequent decline (growth) in housing prices could mute the full impact of preferences on native demographic change. ${ }^{10}$

\footnotetext{
${ }^{9}$ It is straightforward to sketch micro-foundations of equation (1) as arising from the addition of outcomes of a simple individual random utility maximization model (RUM) à la McFadden (1974) or from a RUM model with more general error structures, such as the one introduced by Bertoli, Brücker, and FernándezHuertas Moraga (2016).

${ }^{10}$ Hedonic models (Rosen, 1974) capture this process, and sometimes are specified to include ethnic composition as a local attribute (Wong, 2013). There is a large extant number of residential general equilibrium models that combine ethnic preferences with housing supply and mobility outcomes. We cannot add much here to that extensive literature, so we refer the reader to existing work. The literature about tipping points and segregation is rich, starting with Schelling (1971); more recent examples are Bond and Coulson (1989) or
} 
The empirical size of $\beta$ determines the patterns of spatial segregation, establishing future social and human capital externalities between the native and immigrant populations (Borjas, 1995; Benabou, 1993). There are, however, further interesting implications about the nature of native preferences arising from the empirical sign and magnitude of this parameter. If $\beta>0$, after controlling for all other relevant neighborhood characteristics and shocks, one can conclude that the arrival of new immigrants into a neighborhood made it more desirable to natives. Increased population must be accommodated via a combination of new housing supply and higher residential densities, with housing prices increasing.

With $0>\beta \geq-1$, immigrant destinations are growing, but the evidence is consistent with a number of alternative interpretations: (i) a simple mechanical relationship: as native families exit randomly, they are replaced by immigrant households living at higher residential densities; (ii) a price-displacement story, where immigrant arrivals push up housing prices, thereby crowding out some natives; (iii) a native-flight story, whereby natives dislike the presence of foreigners at the margin, but these preferences are not very strong and lower housing prices compensate for many of them to stay.

Hypothesis (i) implies home values to be unchanged and, therefore, new housing supply in immigrant-destination areas not to be significantly different from comparable untreated neighborhoods. Hypothesis (ii) entails higher prices and - on average - more construction in neighborhoods that see immigrant arrivals. Hypothesis (iii) implies lower prices and - on average - less construction than in identical control neighborhoods, with population growth being solely accommodated via increased residential densities of immigrants.

When $\beta<-1$ the neighborhood is losing population and the evidence unambiguously points to the existence of nativist ethnic preferences: the area became less attractive to natives compared to otherwise identical locations, despite the fact that housing there is easier to get by. Home values should be growing more slowly than in untreated neighborhoods. ${ }^{11}$

Pancs and Vriend (2007). The urban economics literature has also a strong tradition of deploying segregation models with spatial features, as in Bailey (1959), Yinger (1976), Courant and Yinger (1977), or Kanemoto (1980). The online appendix in Saiz and Wachter (2011) provides a stylized model that incorporates most of the salient issues at arguably low expositional cost.

${ }^{11}$ An alternative explanation for $\beta<-1$ is that immigrants in destination areas live at lower residential densities (less individuals per house), while paying the same or higher prices per square meter. This hypothesis is counterfactual to the Spanish case, where all the groups with growing presence in the country actually have been shown to live at higher residential densities than comparable native households. We confirm this fact in section 4.2, but the pattern has been amply documented earlier (Onrubia, 2010). 


\subsection{Simultaneity and Omitted Variables}

Estimating the model in equation (1) directly is bound to produce biased estimates. Consider the additional equation behind the data generation process for the relative growth of the immigrant population in neighborhood $k$, of city $m$, at time $t$ :

$$
\begin{array}{r}
\Delta i m_{k, m, t}=\pi_{m, t}+\delta_{i m_{k, m, t-1}}+\rho \cdot F\left(\Delta I M_{m, t}\right) \cdot i m_{k, m, t-1} \\
+X_{k, m, t-1}^{\prime} \Omega+\gamma_{i} S_{k, m, t}+\alpha \Delta n a t_{k, m, t}+\xi_{k, m, t}
\end{array}
$$

Here, $F\left(\Delta I M_{m, t}\right)$ stands for a function of the total number of immigrants arrived in the metropolitan area $m$ between $t$ and $t-1$. Immigrants are likely - as natives - to be attracted to new employment opportunities and amenities $\left(S_{k, m, t}\right)$, which will bias upward estimates of $\beta$ in equation (1). In addition, immigrant inflows are likely to be endogenous to native exits via mechanically taking advantage of new vacancies or reduced competition in the housing market - as captured by the parameter $\alpha$. This will exaggerate estimates of native flight. ${ }^{12}$ The relative strength of these two effects determines the OLS bias of $\beta$ in equation 1.

New immigrants are also likely to be attracted to neighborhoods with a strong presence of co-ethnics. In equation (2), we capture this effect with $i m_{k, m, t-1}$. Of course, we expect more inflows into ethnic neighborhoods of metropolitan areas that are experiencing a larger immigrant intake of the relevant group, as captured by $F\left(\Delta I M_{m, t}\right) \cdot i m_{k, m, t-1}$. This expectation has been empirically corroborated by Saiz and Wachter (2011) and Kasy (2015).

We thus use the interactions between lagged population shares by immigrant group and its metropolitan inflow levels as instruments. Concretely, we generate predictions of total immigrant inflows from developing countries (superscript DG) into neighborhood $k$, in metro area $m$, in period $t\left(\widetilde{\Delta i m_{k, m, t}^{D G}}\right)$ using:

$$
\widetilde{\Delta i m_{k, m, t}^{D G}}=\sum_{\forall g}\left(i m_{k, m, t-1}^{g} \cdot \frac{I M_{m, t}^{g}}{I M_{m, t-1}^{g}}\right)
$$

$g$ denotes an ethnic group, proxied by country of birth within the subset $D G$, and $I M_{m, t}^{g}=$

$\sum_{k \in K^{m}} i m_{k, m, t}^{g}$, with $K^{m}$ representing the set of neighborhoods in metro area $m$. We are therefore projecting the growth rate of each ethnic group by each metro area to forecast its

\footnotetext{
${ }^{12}$ A similar argument is offered by Andersson, Berg, and Dahlberg (2018).
} 
expansion at the neighborhood level. Similar calculations are produced to generate instruments for migratory flows from developed countries (which we superscript by $D D$ ).

Importantly, our IV specifications also control for metropolitan area fixed effects, and for the initial concentration of immigrants in each subset (this is $\sum_{\forall g} i m_{k, m, t-1}^{g}$ ), and are thus not identified by general metropolitan shocks or by initial migrant concentrations per se. Rather, identification relies on the interaction between country-by-metro-specific migrant shocks and lagged micro settlement patterns by country and neighborhood.

For instance, consider two hypothetical cities: A and B. Both contain observationallyequivalent neighborhoods 1 and 2. Neighborhood 1 in each city contains a substantial and identical number of Ecuadorian immigrants at $t-1$, while neighborhood two houses a similar contingent of Bolivians. If city A receives larger subsequent inflows of Ecuadorians and city B larger contingents of Bolivians, we would expect neighborhood 1 in city A to be more substantially treated by a higher immigration dosage, whereas the high-treatment

neighborhood in city B should be 2 . By including lagged immigrant levels $\left(i m_{k, m, t-1}\right)$ on the right-hand-side, we directly control for potential delayed demographic responses to the initial immigrant settlement patterns, and for unobservables that could be correlated with them. Since we also control for a very large number of amenities, these types of neighborhoods must have been very similar ex ante. In this historical natural experiment, citizens in year 2000 could not have possibly forecasted the large size and speed of future migratory inflows in the country - and less so their ethnic and metropolitan distribution. Therefore, changing dynamics in these neighborhoods are bound to be generated by unexpected ex post differences in the levels of new immigrant arrivals.

\subsection{New Neighborhoods and Segregation Models}

Due to the housing boom, many neighborhoods that were empty in 2001 had become heavily populated by 2008. New residential developments were also destinations for the foreign-born. And it was precisely the metropolitan areas receiving large migratory flows that saw more construction (González and Ortega, 2013). It is critical to separately study the demographic dynamics of these new or rapidly-growing neighborhoods. Sidestepping their analysis may yield an incomplete picture of ethnic segregation in cities with robust demographic growth.

To illustrate this point, consider a hypothetical city with 10 neighborhoods, 3 of which are empty in an initial period $(t=0)$, as displayed in Figure 4. The share of minorities in each 
neighborhood is scaled according to the relative size of their blue area. Consider the pattern of demographic growth ten years later, at $t=10$ illustrated in Figure 4. Neighborhood 2adjacent to a minority enclave - "tips" into becoming an enclave itself. However, previouslyundeveloped neighborhoods- $\mathrm{N}=8,9$, and 10-become recipients of inflows from both ethnic groups, with substantial integration happening there at $t=10$.

Figure (4)

Empirical tipping-point models (Card, Mas, and Rothstein, 2008) study the ability of nonlinearities in past minority shares to predict subsequent demographic change. In this example, such models would find evidence of tipping behavior, since the neighborhood with a large minority share transitioned towards complete segregation. But substantial ethnic mixing was happening in new developments, painting a more optimistic picture. In our example, subsequent research (data from, say, $t=20$ ) could confirm the stability of the mixedethnicity patterns in neighborhoods 8,9 , and 10 . Yet the micro data used in these studies tends to come from decennial censuses - which themselves have 3-4 year data-processing times - implying a more than 13-year lag in the identification of new integrated urban patterns.

The same caveat applies to outflow-inflow studies such as Saiz and Wachter (2011). Strong instruments based on lagged demographic characteristics cannot be obtained in areas with no - or very sparse - previous settlement. In the example, using past minority shares combined with city-wide growth to form instruments would achieve identification of the large displacement effect in neighborhood 2, omitting the dynamics of new residential developments. Existing empirical techniques thus estimate a Local Average Treatment Effect (LATE) that could be relatively less relevant to overall segregation dynamics in rapidly growing cities. In our example, the LATE identified by both tipping and outflow-inflow models corresponds to the impact of growing minority concentrations on majority-population flight in the dense urban areas that have historically bordered minority enclaves. The types of minority households who move there, and the expectations of non-minority neighbors about the desirability and feasibility of integrated outcomes could be different in such communities, as opposed to in ex-novo developments. In our work, we will thus add descriptive evidence of patterns occurring in rapidly-growing suburban developments. 


\section{Results}

\subsection{Outflow-Inflow: OLS and 2SLS Specifications}

We estimate an augmented OLS version of equation (1). Empirically, we separate neighborhood inflows of foreign-born individuals from developing countries (denoted by $\Delta i m_{k, m, t}^{D G}$ ) from those from developed countries $\left(\Delta i m_{k, m, t}^{D D}\right)$. Our focus is on the former, mainly immigrants from Latin America, Africa, Eastern Europe, and Asia. Individuals moving from developed countries - many of them retirees or lifestyle migrants - displayed very different residential behavior, never featured prominently on the local debates about the impact of immigration, and arrived in much smaller numbers.

Our randomly-defined neighborhoods (squares in a grid) contain many instances of zero or very small population, which dissuades us from normalizing by dividing net native flows by the local initial population. Alternatively, we control for a flexible function (quartic polynomial) of population in 2001 ( $p o p_{k, m, t-1}$ ), and include a dummy variable for neighborhoods that were empty initially $\left(e m p t y_{k, m, t-1}\right)$. Our results using this scaling approach are very similar to those using changes in the native population as a share of lagged total population in the subsample of neighborhoods with a substantial denominator. Given the preponderance of sparsely-populated grid squares, all regressions are weighted using population at baseline, so that they are representative of the impacts experienced by the average citizen. The empirical model that we estimate is thus:

$$
\begin{aligned}
\Delta n a t_{k, m, t}=\theta_{m, t} & +\beta^{D G} \Delta i m_{k, m, t}^{D G}+\beta^{D D} \Delta i m_{k, m, t}^{D D}+\sum_{i=1}^{4} \kappa_{i} p o p_{k, m, t-1}^{i} \\
& +\lambda \cdot \text { empty }_{k, m, t-1}+A_{k, m, t}^{\prime} \gamma_{n}^{A}+X_{k, m, t-1}^{\prime} \Omega_{n}^{S}+u_{k, m, t}
\end{aligned}
$$

where $A_{k, m, t}$ is a vector of amenities (gravities) and $X_{k, m, t-1}$ is a vector of socioeconomic characteristics at baseline. In our application, we have $t=2008$ and $t-1=2001$ and are thus estimating a long-differences model of changes between 2001 and 2008. We believe the low-frequency variance in the data to contain much less error than annual changes. Moreover, local demographic trends were very persistent, and most of the true signal contained in the annual changes is well-captured by the long-difference model.

Our population variables $\left(\Delta n a t_{k, m, t}, \Delta i m_{k, m, t}^{D G}, \Delta i m_{k, m, t}^{D D}\right.$, and $\left.p o p_{k, m, t-1}\right)$ are computed excluding children 0-15 years old, in order to avoid capturing native growth due to locally- 
born children of immigrants. We include mortality and age structure controls: the baseline share of native population in age groups 15-24, 25-44, 45-64, and beyond.

Because we have a very large amount of observable neighborhood characteristics, we saturate the model to avoid omitted variable concerns. We thus control for a dummy for zero population in 2008; distances to population-weighted metro area and municipality centers; and 62 measures of accessibility to amenities. Additionally, we include variables from the 2001 Census capturing social dimensions that can be differentially relevant for immigrants and natives: unemployment rate; share of workers in: construction, housekeeping, hotels, and restaurants; share of housing units by building period; average height of buildings; perceived neighborhood cleanliness; and a number of principal component indexes for transportation choices (car, public transportation, walking to work, etc). Table 2 displays all control variables.

(Table 3)

Column 1 of Table 3 shows descriptive results for a regression including metro area fixed effects, but no other controls. Results display a naive outflow-inflow coefficient of about -0.7 for arrivals from developing countries. As expected, there is a positive association between arrivals from high-income countries and native growth. In column 2 , we introduce the control variables, which substantially mute displacement effects. This suggests that observable characteristics were making these neighborhoods counterfactually less attractive for natives, regardless of immigration. Of course, unobserved local positive shocks in housing and labor markets could still bias the conditional coefficients toward zero.

To avoid results being driven by real-estate-development outliers, we next proceed by excluding grid squares with extreme demographic growth or decline. To define such, we calculate the population growth distribution at the top and bottom 1 percent of the 2001population-weighted squares. The set of neighborhoods between the top and bottom percentiles experienced growth between -25.3 percent and 134.8 percent. We henceforth exclude 4,531 squares with population growth below and above that range and 1,949 squares with no population in 2001 (technically experiencing infinite growth). The areas excluded amount to 22.72 percent of the squares in our metropolitan grids, but to only 2 percent of the metro population in 2001 by definition. Remarkably, the right tail of this set went on to hosting 3.6 percent of the metro population in 2008 due to the construction boom, and will be studied later. Considering only the squares with no such extreme growth or decline 
somewhat increases displacement effects (column 3). ${ }^{13}$

Column 4 (Table 3) presents OLS associations by main region of origin. There is prima facie evidence of displacement effects from African, Asian, Latin American, and Eastern European inflows. The latter two are precisely the groups that were growing more substantially. Nevertheless, standard errors by ethnic group are large and we cannot reject coefficient equality. Column 5 presents 2SLS results using the instruments discussed in section 3.3 and controls for initial immigrant group concentration. Our causal estimates suggest that every 3 immigrants from developing countries arriving into a well-established urban neighborhood displaced one native.

There is evidence of native complementarity with regards to developed-country arrivals but, unfortunately, the estimate has a standard deviation that is almost twice as large as the OLS one in column 3. The instrument is relatively weak for the developed-country group, due to: i) their very low propensity to cluster in specific neighborhoods; ii) the strong persistence in the flows by nationality and neighborhood in the few metro areas where these migrants did cluster. Such clustered migration mostly hailed from Germany and the UK, and tended to settle in concrete areas of a few coastal touristic cities, such as Marbella, Alicante, and Mallorca. The instrument-using differences in metro arrivals interacted by intracity variation in local settlement patterns - has low variance for these groups.

We henceforth omit changes in developed-country migrant density at considerable gain in efficiency: the value of Kleibergen-Paap Wald statistic shoots up sixfold to 842.9 in column 6, because the instrument is always very strong with regards to the settlement of developingcountry immigrants. This omission has no bearing on the substantive interpretation of results, as developed-country migrants only represented 12 percent of total metropolitan inflows. Furthermore, we still include controls for the initial density of this group in 2001, which capture expected trends in the few neighborhoods where they clustered. ${ }^{14}$ The outflowinflow parameter of interest is quite stable: substantially below one and larger than zero in absolute terms.

\footnotetext{
${ }^{13}$ The main-trimmed - sample of 22,043 neighborhoods received 2.07 million adult immigrants from developing nations, while losing 259,447 adult natives.

${ }^{14}$ Results with regards to developing-country immigrants are not sensitive at large to the inclusion of instrumented developed-country migrants. However, the coefficients on the latter do fluctuate across specifications, as would be expected with weak instruments. The main results are also robust to omitting population weights, excluding Barcelona and Madrid, and to omitting 2008-defined POI information.
} 


\subsection{Heterogeneity and Housing Supply}

We next deploy our preferred specification in column 6 of Table 3 to examine a number of hypotheses, some of them involving heterogeneous treatment effects. A potential explanation for the results is that immigrants in Spain may have moved disproportionately to neighborhoods with already low socio-economic status (SES), thereby leaving perceptions about these areas unchanged. Potential negative impacts of immigration on neighborhood perceptions may be driven by their lower SES - as it is evidenced in the US (Saiz and Wachter, 2011) or Sweden (Andersson, Berg, and Dahlberg, 2018). Immigrants from developing countries during this period tended to displayed lower incomes and educational attainment than natives (De la Rica, Glitz, and Ortega, 2014; Ambrosini, Mayr, Peri, and Radu, 2015), and worse outcomes in the labor market conditional on education. A related hypothesis is that - while most of the population displayed ethnic preferences - only higher-income families were able to pay for segregation by moving out to "better" perceived areas. Both hypotheses may imply that immigrants be more likely to spur native flight out of high-SES areas. We therefore segment the sample of neighborhoods by educational attainment. Concretely, we run separate regressions for the neighborhoods that started at the top quartile in the share of college-educated adult individuals, in Table 4, column (1), versus those in the bottom three quartiles (in column 2). Contrary to the hypotheses, we appreciate more displacement in lower SES areas, albeit we cannot reject the null of coefficient equality.

Another potential explanation for low displacement could be the fact that many of the immigrants were Spanish-speaking, and therefore culturally close to the autochthonous population. Results in Table 3 - suggesting average displacement from Latin-American migrantscould have reflected different patterns of self-selection. In column 3 of Table 4, we use separate instruments to distinguish between Latin American immigrants and all others. Results suggest smaller displacement coefficients from Latin Americans, but standard errors are too large to rule out statistical equality.

Per our discussion in section 3.2, results are also consistent with the existence of native flight that was quickly compensated by lower housing price growth, combined with higher residential densities in immigrant households. This hypothesis would imply relatively less new housing supply in treated (high-immigration) neighborhoods, compared to neighborhoods without immigrants, where prices should have been growing faster. While we do not have data on housing prices at the micro level, we do have a measurement of construction 
activity: all new street addresses had to be duly registered as soon as the first resident moved in. Thus, we know how many buildings - corresponding to a unique street address - were erected or removed from the stock. The number of homes in multifamily units tends to be larger in central locations and smaller in far away locales, with single-family units becoming more common in the suburbs. Therefore a new street address does not correspond to the same number of homes across geographies.

However, we can express the number of homes by neighborhood in 2001 as a function of its population and a location-specific parameter $\delta_{k, m}$ : Homes $k, m, t-1 \equiv$ Pop $_{k, m, t-1} \cdot \delta_{k, m}$. Similarly, the initial number of homes can be expressed as the number of street addresses times the number of homes per address $\left(\tau_{k, m}\right):$ Homes $_{k, m, t-1} \equiv$ Buildings $_{k, m, t-1} \cdot \tau_{k, m}$. Therefore, the initial number of buildings is such that: Building $s_{k, m, t-1} \equiv \frac{P o p_{k, m, t-1}}{\left(\tau_{k, m} / \delta_{k, m}\right)}$

Let us consider the hypothesis that potential native population growth happens at established household sizes, but that developing-country immigrant households move into larger ones. Denote the ratio of homes per immigrant person by $\psi \delta_{k, m}$, with $1>\psi>0$. We then expect the number of buildings in our database to grow according to:

$$
\Delta \text { Buildings }_{k, m, t}=\frac{\Delta \text { nat }_{k, m, t}}{\left(\tau_{k, m} / \delta_{k, m}\right)}+\frac{\psi \Delta i m_{k, m, t}^{N W}}{\left(\tau_{k, m} / \delta_{k, m}\right)}
$$

Note that we are writing native outflows as a function of immigrant inflows, and other factors $\left(\nu_{k, m, t}\right): \Delta n a t_{k, m, t}=\beta \Delta i m_{k, m, t}^{D G}+\nu_{k, m, t}$. Combining the previous equations yields:

$$
\Delta \text { Buildings } s_{k, m, t} \cdot\left(\text { Pop }_{k, m, t-1} / \text { Buildings }_{k, m, t-1}\right)=(\psi+\beta) \Delta i m_{k, m, t}^{D G}+\nu_{k, m, t}
$$

Back to Table 4, this suggests studying how the number of new buildings - adjusted by local residential use intensity - responded to immigration inflows. Results are shown in column 4. They suggest that areas receiving a number of immigrants that would have required one extra building at previous native settlement usage intensities, actually saw the appearance of 0.56 new buildings. Because our estimate of $\beta$ hovers around 0.30 , this implies that $\psi \approx 0.86$. Therefore, a way to rationalize the results is by accepting that immigrant households required only about $\frac{3}{4}^{\text {ths }}$ as much space per person as native households in the marginal neighborhoods where the instrument matters.

According to Ajenjo, Blanes, Bosch, Parella, Recio, Martin, and Sintes (2008), each developing-country immigrant housing unit tended to be occupied by 3.85 people, compared to 2.8 people-per units for natives: this corresponds to a ratio of 0.7. Similarly, Reher, Alcala, 
Quinones, Requena, Dominguez, Gimeno, and Stanek (2008), report the average size of the immigrant household at 3.8 persons compared to 2.9 for natives, and the average size of the corresponding housing units as $96 \mathrm{Sq} \mathrm{m}$ and $97.1 \mathrm{Sq} \mathrm{m}$ respectively, implying a ratio of 0.77. Both magnitudes are close to our estimate and well within its statistical range. This implies that a local combination of: (i) mild native displacement, (ii) new housing construction, and (iii) increased residential use intensity, can explain quite well the accommodation of immigrants in the housing market.

Per our discussion earlier, the facts are highly inconsistent with a model of generalized nativism, where we would expect immigrant destinations to see shrinking home values and less construction, due to reduced demand by the marginal native. Results seem more consistent with a housing-market tightness story, whereby new foreign-born arrivals moved in to existing vacancies, thereby mechanically "displacing" counterfactual native movers, and pushed up the overall demand for the neighborhood, spurring more construction.

If the housing market tightness effect was prevalent, we should see less construction and more displacement in more supply-constrained areas. While we do not have measures of supply elasticity by neighborhood, we separate the analysis of neighborhoods in the top quartile by population density in 2001. In a European context, land availability and redevelopment potential are bound to be lower in denser neighborhoods. Back to Table 4, point estimates of the effects of immigrant shocks on housing construction in the densest neighborhoods (column 5) are indeed smaller than in less-dense areas (column 6). In columns 7 and 8 we bring back the change in the native population to the right-hand-side, finding that all of the displacement effects seemed to be driven by the densest areas. These findings are in line with our discussion in section 3.4: pooled 2SLS results may be capturing LATEs in the densest neighborhoods, where the instrument has more variability. While the evidence is broadly consistent with a housing-market tightness story, we cannot reject statistical equivalence between point estimates in columns 5 and 6 , or 7 and 8 respectively at conventional levels.

Finally, we note that all results are robust to using larger quadrants as the geographic unit of analysis, with sides equal to 0.01 degrees, or approximately 1.1 kilometers (Appendix). Point coefficients on displacement are smaller (around -0.2), which is consistent with some of the natives displaced from more narrowly-defined quadrants moving to adjacent areas. However, we cannot reject their statistical equivalence. 


\subsection{Nonlinearities}

The previous specifications assume a linear relationship between immigrant inflows and native outflows. However, native flight could have kicked in or accelerated only at high immigrant concentrations. We now investigate such potential nonlinearities. We first search for potential tipping points following the methods in Card, Mas, and Rothstein (2008). We start by dividing our trimmed sample ${ }^{15}$ into two equally-sized random sets: training and replication. Using the training set, we run a sequence of regressions of the form:

$$
\widehat{\Delta \operatorname{nat}_{k, m, t}}=\theta_{m, t}^{\prime}+d \cdot \mathbf{1}\left[\operatorname{shim}_{k, m, t-1}^{D G}>\mu^{*}\right]+\widehat{\varepsilon}_{k, m, t}
$$

for $0 \leq \mu^{*} \leq M$. Here $\operatorname{shim}_{k, m, t-1}^{D G}$ denotes the population share of developing-country immigrants in 2001 and $\widehat{\Delta \text { at }_{k, m, t}}$ the covariate-adjusted change in the native population in each neighborhood. This variable is adjusted by estimating regressions with the same covariates as in table 3, obtaining the residuals, and adding back the metro's average predicted value. Thus we "partial out" the influence of other covariates on $\Delta n a t_{k, m, t}$, including scaling to polynomials in initial population and all other neighborhood characteristics. $\mu^{*}$ is the level of initial migrant share that could propitiate a discontinuity in native population growth, and $1[\cdot]$ denotes an indicator variable. We set $M=0.50$ and experiment with values of $\mu^{*}$ for all integers between 1 and 49 percent. We then select the $\mu^{*}$ with maximal R-square from the series of training regressions, which turns out to be 4 percent.

Once this candidate for a discontinuity point is identified we test its relevance on the replication using an out-of-sample specification that controls for a quadratic function of the initial immigrant share on "both sides" of $\mu^{*}=0.04\left(f_{0.04}^{+,-}\left(\operatorname{shim}_{k, m, t-1}^{N W}\right)\right)$ as shown below:

$$
\widehat{\Delta \text { nat }_{k, m, t}}=\theta^{\prime \prime}{ }_{m, t}+\Phi \cdot \mathbf{1}\left[\operatorname{shim}_{k, m, t-1}^{N W}>0.04\right]+f_{0.04}^{+,-}\left(\operatorname{shim}_{k, m, t-1}^{N W}\right)+\widehat{\zeta}_{k, m, t}
$$

Our out-of-sample estimates of $\Phi$ reject a discontinuity in native growth at conventional significance levels. The estimation of equation 8 yields a positive coefficient of 62.18 with an estimated standard error of 42.52. The lack of major tipping dynamics can be appreciated graphically in figure 5. On the horizontal axis, we group neighborhoods into 50 bins defined by their initial share of immigrants in 2001, rounded to the closest integer. In the vertical axis, the dots show average change in the covariate-adjusted number of natives within

\footnotetext{
${ }^{15}$ Outlier observations often have zero or very low population base and we cannot credibly identify differences in the initial share of immigrants.
} 
each bin across neighborhoods. The continuous line fits a local-mean smoothed plot of the relationship, with 95 percent confidence intervals delimited by the gray area. Contrary to conventional tipping dynamics, we see a u-shaped relationship: the number of natives seemed to decrease with growing initial immigrant concentrations up to about 10 percent, but then increased for even larger migrant densities. ${ }^{16}$

(Figure 5)

The lack of clear tipping dynamics may be due to low power, since just a few neighborhoods had significant minority concentrations in 2001: for instance only 5 percent of population-weighted quadrants had migrant concentrations above 8.5 percent, and the top percentile was at around 15 percent. Although we have more than 20,000 neighborhoods, the phenomenon may not have acquired the size to detect discernible tipping patterns. In contrast, subsequent arrivals were substantial enough to push many areas beyond potential tipping points. For instance, the neighborhood at the 75th percentile in 2008 already had more than a 13.5 percent immigrant share.

Of course, the final immigrant share in 2008 was directly endogenous to native flows between 2001 and 2008. In order to find potentially exogenous discontinuity points in native residential responses we redeploy our instrumental variable in the following way: we again divide the data into two random search and validation subsamples, expected to be of equal size. We then generate a sequence of tipping-point indicator variables - to use as potential instruments - that take the form:

$$
T \widetilde{T_{k, m, t}^{D G}\left(\mu^{* *}\right)}=\mathbf{1}\left[\frac{i m_{k, m, t-1}^{D G}+\widehat{\Delta i m_{k, m, t}^{D G}}}{\operatorname{pop}_{k, m, t-1}}>\mu^{* *}\right]
$$

Where $\widetilde{\Delta i m_{k, m, t}^{D G}}$ is the shift-share instrument produced in equation 3. We thus examine what happened to neighborhoods that had specialized in 2001 on the nationalities which subsequently grew in their metropolitan area, and whose immigrant shares were thus expected to mechanically exceed $\mu^{* *}$ by 2008. To do so we run a series of 2SLS specifications

\footnotetext{
${ }^{16}$ We use the Epanechnikov kernel and the ROT method to estimate the optimal bandwidth. The U shape becomes more pronounced, with similar inflection points, if we use unadjusted changes in native populations on the y axis. This latter finding confirms the regression results that areas with initial concentrations of immigrant between 0-10 percent tended to have characteristics that would have predicted native decline regardless of migratory inflows.
} 
on the search sample as in column 6 in Table 3 but adding as an additional control an indicator function for neighborhoods that had actually reached the potential tipping threshold $\mu^{* *}$ as of $2008\left(T T_{k, m, t}^{D G}\left(\mu^{* *}\right)=\mathbf{1}\left[\frac{i m_{k, m, t-1}^{D G}+\Delta i m_{k, m, t}^{D G}}{p o p_{k, m, t-1}}>\mu^{* *}\right]\right)$, instrumented by $T T_{k, m, t}^{D G(\mu * *)}$. We search for jumps at immigrant densities that reach 5 percent of the initial population and a series of thresholds at additional five percentage points up to 45 percent. In this sequence of 2SLS models applied to the search sample, we find that the $\mu^{* *}$ that maximizes the t-statistic of the parameter on $T T_{k, m, t-1}^{D G}\left(\mu^{* *}\right)$ corresponds to $\mu^{* *}=0.15$. There is no strong evidence of a discrete jump in the training sample. In fact estimates are positivewith an additional 184.83 natives after the immigrant share had reached 15 percent - but insignificant (s.e.=99.4). This estimate is not significant either in the replication sample, with $T T_{k, m, t}^{\overparen{D G}(0.15)}=69.09$ (s.e. $\left.=64.73\right)$

\subsection{New Suburbs}

Estimates so far show very mild native displacement, coupled with increased construction, and more intense usage of real estate assets in destination neighborhoods. But even these results understate the degree of demographic complementarity between immigrant and native flows in this historical episode. Concurrently to massive immigration, the country was experiencing a real estate development boom.

We find a very strong spatial dimension to the unbalanced growth of the native population. Figures 6 and 7 plot the neighborhoods with net gains in the native population (top) and-because most neighborhoods had positive immigrant entries - those with above average migrant growth (bottom), in the Madrid and Barcelona metro areas respectively.

(Figure 6)

(Figure 7)

In the figures, each circle corresponds to the centroid of a grid quadrant, and its size is proportional to the 2001 population. We color squares in red according to either the gain of natives (upper panel) or to the above-average number of migrant arrivals (lower panel). The upper panels clearly shows that native growth was more widespread far away from the city centers (mostly taking place in newly-built suburban developments). The lower panels, showing above-average migrant growth (more than 780 migrants per grid square in Madrid and 845 in Barcelona), are almost the inverse image.

Figure 8 shows that these patterns extended to all metro areas. Here we display smooth 
plots of the average number of immigrant and native net flows by neighborhood, sorted by the distance to their metropolitan area's central city. The patterns are stark. Metro areas saw average declines in the native population up to around 4 kilometers from the center, where immigrant arrivals from developing countries were at their highest. Beyond that distance, both native and migrant flows were positive, the former increasing monotonically with distance, the latter decreasing.

New development areas hosted most new supply during the real estate boom, so it is not surprising to see population flows in that direction from all groups. But did the two groups tend to collocate? In order to answer this, we now focus on the fastest growing neighborhoods, which we had trimmed out from the previous regressions. These hosted only one percent of the metro population in 2001, but went on to amount to 3.6 percent only seven years later, attracting more than half-a-million natives and more than 85,000 immigrants - close to proportionate to their weights in the resident population. We calculate the conditional metropolitan market share of each new neighborhood with respect to both populations. These are plotted in figure 9. Conditional on population movements to fastgrowing real estate developments, neighborhoods that captured a high proportion of natives from their metro areas also tended to capture a similar proportion of local immigrants. A regression of the conditional market share of natives in each new development on their immigrant market share yields an odds ratio of 0.94 (s.e. 0.01). In practical terms, contingent upon the decision of moving to new housing developments, natives and immigrants tended to collocate strongly.

We can thus speak of two types of neighborhoods: i) central, denser, established neighborhoods, where native displacement happened at relatively mild rates, but more conspicuously; in a few instances even generating the appearance of ghettos due to very large migrant inflows; and ii) suburban new developments, attracting both migrants and natives, where substantial ethnic mixing was happening.

\section{Discussion and Conclusions}

The settlement of immigrants into urban areas of the developed world has become a central policy issue of our times. In many countries, citizens are expressing dissatisfaction with the growing number of foreign-born neighbors by voting for anti-immigrant parties. Some may 
be voting with their feet by disproportionately fleeing the neighborhoods where immigrants move into. In this context, it is important to understand the residential dynamics associated with one of the largest and fastest immigration episodes in recent history. International migration in Spain increased from 3 to 13 percentage points of the population between 1998 and 2008, offering a unique opportunity to examine how native residential location decisions are taken, and the impact of immigration on urban form.

Our empirical analysis represents a comprehensive study, combining microdata on the universe of every residents' exact address with the distance of each building to a large portfolio of amenities, and with socioeconomic characteristics of the neighborhood. We deploy a shift-share instrumental variable similar to Card (2001) but with a micro neighborhood focus (Saiz and Wachter, 2011; Kasy, 2015). Our main finding is that for every three immigrants entering into a settled neighborhood, one native moved away from it. Using discretized versions of our instruments, we do not find evidence of nonlinearities in this displacement effect. We also show that areas receiving a number of immigrants that would have required one extra building at previous native settlement densities actually saw the additional construction of 0.5 new buildings. The results can be fully rationalized if the number of persons per immigrant household were about $\frac{1}{3}$ rd higher than in native ones. This is exactly consistent with measurements by other authors using household surveys.

We also find some suggestive evidence consistent with the fact that such displacement was more prevalent in supply-constrained areas. In less-constrained areas, developers simply built more. The combination of rather mild displacement with substantive new construction in destination neighborhoods is at odds with the existence of strong segregationist behavior. The latter would imply lower housing prices and less supply in neighborhoods treated by immigrant inflows.

We also find that displacement may have been smaller in areas with higher socioeconomic status. This is not consistent with a model of simple, homogeneous, nativist preferences, whereby better-off individuals should display higher willingness-to-pay to indulge in their discriminatory tastes. Because developing-country migrants were less educated on average, the evidence is not prima facie consistent either with flight motivated by very local SES differentials. However we do not have the exact micro data on the SES of the natives leaving each type of neighborhood, as in Andersson, Berg, and Dahlberg (2018), and we cannot rule flight from high-SES individuals happening disproportionately in low SES neighborhoods. 
Some of the methodological insights in this study can be exported to other environments. The study of new housing supply should be included in research about residential dynamics. More saliently, we establish the fact that conventional outflow-inflow or tipping-point methods measure local average treatment effects in established, denser communities. Such estimates are of considerable importance in the most visible areas of the city. But they may understate the degree of ethnic mixing in growing metros if - as we also find here - new residential developments jointly attracted similar proportions of both majority and minority populations. Conventional methods based on lagged demographics may therefore provide the complete picture in Cleveland, Chicago, or Marseille, but may be less suitable to understanding patterns of segregation in booming Phoenix, Dublin, or Shenzen.

The results in the paper are quite benign from the point of view of observers worried about ethnic segregation in Spain. Of course, the external validity of our quantitative conclusions to other environments outside of this country is unknown. Nevertheless, some observations may be pertinent to explain why this episode was different, and to accommodate the evidence into a more generalized theory of native flight.

1. Arguably, planning and zoning institutions were anti-segregation. The Spanish Constitution of 1978 enforced the declaration of human rights and other international conventions de jure. Because immigration mostly happened late in history-and Spaniards perceived themselves as racially homogeneous prior to it - the country had not developed explicit segregationist institutions in the modern era. ${ }^{17}$ In other environments, these institutions may have created bad equilibria that are difficult to undo (Rothstein, 2017). Note further that many of the urbanized parts of the country have been settled for millennia. Therefore, zoning in the densest areas partially accommodates pre-existing patterns. However, new supply does arise via: i) upzoning; ii) rezoning of outlying or suburban areas to allow for urban development. Federal laws in the period under consideration mandated value capture by the local authorities taking the form of land set-asides for affordable housing ("Viviendas de Protección Oficial"). The Law enforced that a percentage of at least 30 percent of rezoned/upzoned land had to be thus devoted to affordable housing.

Arguably, right-wing parties - which tend nowadays to be more vocal trying to capital-

\footnotetext{
${ }^{17}$ Undeniably, however, such self-perceived ethnic homogeneity had been achieved through violent episodes of ethnic cleansing and anti-semitic, anti-Muslim, and racial purity laws in pre-Modern times
} 
ize anti-immigration sentiment - happened to be those that also tend to favor more real estate development at the local level (Solé-Ollé and Viladecans-Marsal, 2013, 2012). Left-wing parties were generally anti-development, but tended to favor immigrants in most other dimensions (e.g. social policies). Therefore, a citizen trying to leverage her vote to reduce the inflow of immigrants in her municipality would have faced a difficult choice.

2. A very large portion of the immigrants came from countries with relative cultural proximity (Latin America, Eastern Europe). Albeit not statistically conclusive, there is some evidence to suggest smaller displacement effects arising from same-language Latin American arrivals.

3. The availability of private schools - 60 percent of them Catholic - allowed some native parents to avoid schooling their children in facilities with large migrant shares without moving. Most private schools are subsidized by the government, requiring only an average "voluntary" payment of $€ 500$ per child and year from parents. These schools are generally accessible in dense areas. The country had been experiencing a decline in the number of native pupils - due to low fertility rates. Therefore, private schools were happy to capture a larger market share. Farrè, Ortega, and Tanaka (2018) find very strong evidence of this, arguing that the immigrant boom caused a 7 percentage-point increase in the share of households using private schools.

4. Spain has one of the lowest household mobility rates of the OECD. According to Andrews and Caldera Sánchez (2011), a household in the US moves every 9.5 years on average, as opposed to every 25 years in Spain. Given the late emancipation age in this country - median 26 and 28 for females and males respectively (Martínez Granado and Ruiz Castillo, 2002) - this implies that many households only move once after initial family formation. Arbitrarily large moving costs imply that negative shocks to perceived neighborhood quality affect mostly welfare - via reduced consumer surplusesbut not necessarily residential behavior. Less-mobile households may express their discontent through voice and vote, as opposed to exit (Hirschman, 1970), a hypothesis that we red-flag for future research.

5. The speed and magnitude of the immigrant inflows may have made it difficult to forecast future immigrant concentrations in the choice set of alternative neighborhoods 
available to the native population (Blair, 2014). As in global or network games (Carlsson and Van Damme, 1993; Jackson and Yariv, 2007), the decision to flee by natives may endogenously depend on the formation of higher order beliefs about the expectations of other natives in the neighborhood or network. Native flight could be more likely when most natives believe that their current neighborhood will tip and that potential destination neighborhoods are safe from ethnic intrusion, a point made theoretically by Frankel and Pauzner (2002). The environment in our research was likely to make segregationist coordination difficult. The processes surrounding the formation of beliefs around neighborhood ethnic change, and their interaction with the speed and past experience of minority inflows in the city represent fascinating topics for future research.

\section{References}

Accetturo, A., F. Manaresi, S. Mocetti, and E. Olivieri (2014): “Don't stand so close to me: The urban impact of immigration," Regional Science and Urban Economics, $45(\mathrm{C}), 45-56$.

Ajenjo, M., A. Blanes, J. Bosch, S. Parella, A. Recio, J. S. Martin, and E. Sintes (2008): Les condicions de vida de la població immigrada a Catalunya, Col-lecció Politiques: Fundació Jaume Bofill. Editorial Mediterrània, Barcelona.

Ambrosini, J. W., K. Mayr, G. Peri, and D. Radu (2015): "The selection of migrants and returnees in Romania: Evidence and long-run implications," Economics of Transition, $23(4), 753-793$.

Amuedo-Dorantes, C., And S. De la RiCA (2007): "Labour market assimilation of recent immigrants in Spain," British Journal of Industrial Relations, 45(2), 257-284.

Andersson, H., H. Berg, and M. DahlberG (2018): "Migrating natives and foreign immigration: Is there a preference for ethnic residential homogeneity?," IFAU Working Paper Series, (12).

Andrews, D., And A. Caldera SÁnchez (2011): "Residential Mobility and Public Policy in OECD Countries," OECD Journal, Economic Studies, 2011(1). 
BAiley, M. J. (1959): "Note on the Economics of Residential Zoning and Urban Renewal," Land Economics, 35(3), 288-292.

Ballester, C., And M. Vorsatz (2014): "Random Walk-Based Segregation Measures," The Review of Economics and Statistics, 96(3), 383-401.

Bell, B., and S. Machin (2013): "Immigrant Enclaves And Crime," Journal of Regional Science, 53(1), 118-141.

Benabou, R. (1993): "Workings of a City: Location, Education, and Production," The Quarterly Journal of Economics, 108(3), 619-652.

Bertoli, S., H. Brücker, and J. Fernández-Huertas Moraga (2016): "The European crisis and migration to Germany," Regional Science and Urban Economics, 60(C), $61-72$.

Bertoli, S., and J. Fernández-Huertas Moraga (2013): "Multilateral resistance to migration," Journal of Development Economics, 102(C), 79-100.

Blair, P. Q. (2014): "The Effect of Outside Options on Neighborhood Tipping Points," Ph.D. thesis, Ph. D. thesis, University of Pennsylvania.

Blázquez, M., C. Llano, and J. Moral (2010): "Commuting Times: Is There Any Penalty for Immigrants?," Urban Studies, 47(8), 1663-1686.

Boeri, T., M. D. Philippis, E. Patacchini, and M. Pellizzari (2015): "Immigration, Housing Discrimination and Employment," Economic Journal, 125(586), 82-114.

Bond, E. W., And N. Coulson (1989): "Externalities, filtering, and neighborhood change," Journal of Urban Economics, 26(2), 231 - 249.

BorJas, G. J. (1995): "Ethnicity, Neighborhoods, and Human-Capital Externalities," The American Economic Review, 85(3), 365-390.

(2013): "The analytics of the wage effect of immigration," IZA Journal of Migration, $2(1), 22$.

BorJas, G. J., And J. MonRas (2017): "The labour market consequences of refugee supply shocks," Economic Policy, 32(91), 361-413. 
Bosch, M., M. A. Carnero, and L. Farré (2010): "Information and discrimination in the rental housing market: Evidence from a field experiment," Regional Science and Urban Economics, 40(1), 11-19.

Brücker, H., S. Fachin, and A. Venturini (2011): "Do foreigners replace native immigrants? A panel cointegration analysis of internal migration in Italy," Economic Modelling, 28(3), 1078-1089.

CARD, D. (2001): "Immigrant Inflows, Native Outflows, and the Local Labor Market Impacts of Higher Immigration," Journal of Labor Economics, University of Chicago Press, 19(1), 22-64.

Card, D., A. Mas, and J. Rothstein (2008): "Tipping and the Dynamics of Segregation," The Quarterly Journal of Economics, 123(1), 177-218.

Carlsson, H., and E. Van Damme (1993): "Global games and equilibrium selection," Econometrica: Journal of the Econometric Society, pp. 989-1018.

Cea D'ancona, M. A., and M. S. Valles Martínez (2014): Evolución del racismo, la xenofobia y otras formas conexas de intolerancia en España [Informe 2013]. Subdirección General de Información Administrativa y Publicaciones. Ministerio de Empleo y Seguridad Social. Madrid.

Clemens, M. A., and J. Hunt (2017): "The Labor Market Effects of Refugee Waves: Reconciling Conflicting Results," NBER Working Papers 23433, National Bureau of Economic Research, Inc.

Courant, P. N., and J. Yinger (1977): "On models of racial prejudice and urban residential structure," Journal of Urban Economics, 4(3), 272-291.

Cutler, D. M., E. L. Glaeser, and J. L. Vigdor (2008): "Is the Melting Pot Still Hot? Explaining the Resurgence of Immigrant Segregation," The Review of Economics and Statistics, 90(3), 478-497.

Damm, A. P. (2009): "Ethnic Enclaves and Immigrant Labor Market Outcomes: QuasiExperimental Evidence," Journal of Labor Economics, 27(2), 281-314. 
De la Rica, S., A. Glitz, and F. Ortega (2014): "Immigration in Spain: what have we learned from recent evidence?," Cuadernos económicos de ICE, (87), 9-28.

De la Roca, J. (2017): "Selection in initial and return migration: Evidence from moves across Spanish cities," Journal of Urban Economics, 100, 33-53.

De la Roca, J., and D. Puga (2017): "Learning By Working In Big Cities," Review of Economic Studies, 84(1), 106-142.

Docquier, F., C. Ozden, and G. Peri (2014): "The Labour Market Effects of Immigration and Emigration in OECD Countries," The Economic Journal, 124(579), 1106-1145.

Dustmann, C., and I. P. Preston (2007): "Racial and Economic Factors in Attitudes to Immigration," The B.E. Journal of Economic Analysis \& Policy, 7(1), 1-41.

EchazArra, A. (2010): "Segregación residencial de los extranjeros en el área metropolitana de Madrid. Un análisis cuantitativo," Revista Internacional de Sociología (RIS), 68(1), $165-197$.

Edin, P.-A., P. Fredriksson, and O. Åslund (2003): "Ethnic Enclaves And The Economic Success Of Immigrants - Evidence From A Natural Experiment," The Quarterly Journal of Economics, 118(1), 329-357.

ESRI (2009): StreetMap Premium Europe NAVTEQ 2009 Release 2.

Farrè, L., F. Ortega, and R. Tanaka (2018): "Immigration and the public-private school choice," Labour Economics, 51(C), 184-201.

Fernández-Huertas Moraga, J., A. Ferrer, and A. Saiz (2011): "Localización de los inmigrantes y preferencias residenciales de la población autóctona: Nuevos guetos?," mimeo.

Frankel, D. M., And A. Pauzner (2002): "Expectations and the timing of neighborhood change," Journal of Urban Economics, 51(2), 295-314.

FriedberG, R. M. (2001): "The Impact Of Mass Migration On The Israeli Labor Market," The Quarterly Journal of Economics, 116(4), 1373-1408. 
GARCíA-López, M. (2012): "Urban spatial structure, suburbanization and transportation in Barcelona," Journal of Urban Economics, 72(2-3), 176 - 190.

Gautier, P. A., A. Siegmann, and A. Van Vuuren (2009): "Terrorism and attitudes towards minorities: The effect of the Theo van Gogh murder on house prices in Amsterdam," Journal of Urban Economics, 65(2), 113-126.

Giulietti, C. (2009): "Immigration and displacement across local labour markets," Discussion Paper Series In Economics And Econometrics, Economics Division, School of Social Sciences, University of Southampton 0917, Economics Division, School of Social Sciences, University of Southampton.

GonzÁlez, L., And F. ORtega (2013): "Immigration And Housing Booms: Evidence From Spain," Journal of Regional Science, 53(1), 37-59.

Hatton, T. J., And M. TAni (2005): "Immigration and Inter-Regional Mobility in the UK, 1982-2000," Economic Journal, 115(507), F342-F358.

Hirschman, A. O. (1970): Exit, voice, and loyalty: Responses to decline in firms, organizations, and states, vol. 25. Harvard university press.

INE (2005): Censo de Población y Viviendas. Volumen IV. Indicadores inframunicipales. Secciones censales y unidades poblacionales CD Rom. Madrid. (2009): Microdatos del Padrón Municipal de Habitantes. Madrid.

JACKSON, M. O., AND L. YARIV (2007): "Diffusion of behavior and equilibrium properties in network games," The American economic review, 97(2), 92-98.

Jaeger, D. A., J. Ruist, And J. Stuhler (2018): "Shift-Share Instruments and the Impact of Immigration," NBER Working Papers 24285, National Bureau of Economic Research, Inc.

Kanemoto, Y. (1980): "Externality, migration, and urban crises," Journal of Urban Economics, 8(2), 150-164.

KASY, M. (2015): "Identification in a model of sorting with social externalities and the causes of urban segregation," Journal of Urban Economics, 85, 16-33. 
Logan, J. R., W. Zhang, R. Turner, and A. Shertzer (2015): "Creating the black ghetto: Black residential patterns before and during the Great Migration," The Annals of the American Academy of Political and Social Science, 660(1), 18-35.

Martínez Granado, M., and J. Ruiz Castillo (2002): "The Decisions of Spanish Youth, A Cross-Section Study," Journal of Population Economics, 15(2), 305-330.

Massey, D. S., and N. A. Denton (1988): "The Dimensions of Residential Segregation," Social Forces, 67(2), 281-315.

Maza, A., J. Villaverde, and M. Hierro (2013): "Explaining the settlement patterns of foreigners in Spain," Applied Geography, 40(0), 11 - 20.

McFadden, D. (1974): "Conditional logit analysis of qualitative choice behavior," in Frontiers in Econometrics, ed. by P. Zarembka, pp. 105-142. New York: Academic Press.

Ministerio de Vivienda (2007): Atlas Estadístico de las Áreas Urbanas de España 2006. Centro de Publicaciones. Secretaría General Técnica. Ministerio de Vivienda. Madrid.

Nicodemo, C., And J. M. Raya (2012): "Change in the distribution of house prices across Spanish cities," Regional Science and Urban Economics, 42(4), 739-748.

OECD (2009): Panorama de la Educacion 2009.

Onrubia, J. (2010): "Vivienda e inmigración en España: situación y políticas," Presupesto y Gasto Público, (61), 273-310.

Pancs, R., AND N. J. VRIEnd (2007): "Schelling's spatial proximity model of segregation revisited," Journal of Public Economics, 91(1-2), 1- 24.

Pareja-Eastaway, M. (2009): "The Effects Of The Spanish Housing System On The Settlement Patterns Of Immigrants," Tijdschrift voor Economische en Sociale Geografie, $100(4), 519-534$.

Reher, D.-S., L. C. Alchla, F. G. Quinones, M. Requena, M. I. S. Dominguez, A. S. Gimeno, and M. Stanek (2008): Informe Encuesta Nacional de Inmigrantes (ENI - 2007), INE Documentos de Trabajo. Instituto Nacional de Estadistica, Madrid. 
RodríGuez-Planas, N., ANd N. Nollenberger (2016): "Labor market integration of new immigrants in Spain," IZA Journal of Labor Policy, 5(1), 4.

Rosen, S. (1974): "Hedonic Prices and Implicit Markets: Product Differentiation in Pure Competition," Journal of Political Economy, 82(1), 34-55.

Rothstein, R. (2017): The color of law: A forgotten history of how our government segregated America. Liveright Publishing.

Saiz, A., and S. Wachter (2011): "Immigration and the Neighborhood," American Economic Journal: Economic Policy, 3(2), 169-88.

SChelling, T. C. (1971): "Dynamic models of segregation?" Journal of mathematical sociology, 1(2), 143-186.

Shertzer, A., and R. Walsh (2016): "Racial Sorting and the Emergence of Segregation in American Cities," NBER Working Paper Series, (WP 22077).

Solé-Ollé, A., and E. Viladecans-Marsal (2012): "Lobbying, political competition, and local land supply: recent evidence from Spain," Journal of Public economics, 96(1-2), $10-19$.

(2013): "Do political parties matter for local land use policies?," Journal of Urban Economics, 78, 42-56.

Verdugo, G. (2011): "Public Housing and Residential Segregation of Immigrants in France, 1968-1999," Population (english edition), Institut National d'Études Démographiques (INED), 66(1), 169-193.

Wong, M. (2013): "Estimating Ethnic Preferences Using Ethnic Housing Quotas in Singapore," Review of Economic Studies, 80(3), 1178-1214.

World BANK (2013): World Development Indicators. http://databank.worldbank.org.

YiNGER, J. (1976): "Racial prejudice and racial residential segregation in an urban model," Journal of Urban economics, 3(4), 383-396. 


\section{A Tables and Figures}

Table 1: Evolution of the Spanish native and foreign-born population in the Municipal Registry

\section{Year Population Immigrants Share}

\begin{tabular}{cccc}
\hline \hline & & & \\
1998 & $39,852,650$ & $1,173,767$ & $2.9 \%$ \\
1999 & $40,202,158$ & $1,259,054$ & $3.1 \%$ \\
2000 & $40,499,790$ & $1,472,458$ & $3.6 \%$ \\
2001 & $41,116,842$ & $1,969,269$ & $4.8 \%$ \\
2002 & $41,837,894$ & $2,594,052$ & $6.2 \%$ \\
2003 & $42,717,064$ & $3,302,440$ & $7.7 \%$ \\
2004 & $43,197,684$ & $3,693,806$ & $8.6 \%$ \\
2005 & $44,108,530$ & $4,391,484$ & $10.0 \%$ \\
2006 & $44,708,964$ & $4,837,622$ & $10.8 \%$ \\
2007 & $45,200,737$ & $5,249,993$ & $11.6 \%$ \\
2008 & $46,157,822$ & $6,044,528$ & $13.1 \%$
\end{tabular}

Source: own elaboration on data from INE (2009) 
Table 2: Summary Statistics for Neighborhoods in Spanish Metro Areas (2001-2008)

\begin{tabular}{|c|c|c|c|c|}
\hline Variable & Average & Std. Dev. & Min. & Max. \\
\hline$\Delta n a t_{k, m, 2001 \_2008}$ & -256.864 & 705.095 & -4517 & 5160 \\
\hline$\Delta i m_{k, m, 2001 \_2008}^{D G}$ & 431.047 & 526.112 & -194.861 & 5949.989 \\
\hline$\Delta i m_{k, m, 2001 \_2008}^{D D}$ & 36.729 & 129.002 & -1481.075 & 3506.53 \\
\hline$i m_{k, m, 2001}^{D G}$ & 180.166 & 248.36 & 0 & 2370.77 \\
\hline$i m_{k, m, 2001}^{D D}$ & 65.933 & 131.387 & 0 & 3269.768 \\
\hline $\operatorname{pop}_{k, m, 2001}$ & 4670.805 & 3944.83 & 1 & 25139 \\
\hline Share of pop. Aged 15-24 & 0.139 & 0.033 & 0 & 1 \\
\hline Share of pop. Aged 25-44 & 0.323 & 0.047 & 0 & 1 \\
\hline Share of pop. Aged 45-64 & 0.234 & 0.041 & 0 & 1 \\
\hline Share of pop. Aged $65+$ & 0.17 & 0.072 & 0 & 1 \\
\hline Unemployment rate & 13.497 & 5.825 & 0 & 68.332 \\
\hline Share construction employment & 9.685 & 4.907 & 0 & 48.68 \\
\hline Share hospitality employment & 5.837 & 3.878 & 0 & 53.97 \\
\hline Share personal services employment & 3.248 & 1.061 & 0 & 10.705 \\
\hline Share buildings from 1900-1920 & 2.219 & 3.926 & 0 & 97.77 \\
\hline Share buildings from 1921-1940 & 3.378 & 5.184 & 0 & 90.169 \\
\hline Share buildings from 1941-1950 & 3.772 & 4.757 & 0 & 99.92 \\
\hline Share buildings from 1951-1960 & 9.356 & 9.064 & 0 & 99.62 \\
\hline Share buildings from 1961-1970 & 20.746 & 15.586 & 0 & 100 \\
\hline Share buildings from 1971-1980 & 26.211 & 17.082 & 0 & 100 \\
\hline Share buildings from 1981-1990 & 12.182 & 11.909 & 0 & 100 \\
\hline Car use index & 11.18 & 15.826 & -18.71 & 81.495 \\
\hline Pedestrian index & 43.145 & 13.24 & 0 & 85.789 \\
\hline Building height index & 135.599 & 72.925 & -61.464 & 254.784 \\
\hline Neighborhood quality indexx & 86.493 & 39.893 & -25.183 & 226.651 \\
\hline Log distance to metro area center & 1.135 & 1.028 & -4.26 & 5.412 \\
\hline Log distance to municipality center & -0.065 & 1.007 & -4.999 & 5.429 \\
\hline \multicolumn{5}{|l|}{ Gravities* $* 10^{6}$} \\
\hline Exits (from highways or roads) & 9.754 & 104.481 & 0.034 & 22459.84 \\
\hline
\end{tabular}




\begin{tabular}{|c|c|c|c|c|}
\hline Winery & 0.9 & 27.27 & 0 & 1961.40 \\
\hline ATM & 19097.636 & 731449.33 & 0.11 & 36176196 \\
\hline Train Station & 4.06 & 56.041 & 0 & 14831.50 \\
\hline Commuter Rail Station & 135.15 & 1559.65 & 0 & 155200.22 \\
\hline Bus Station & 8.07 & 151.51 & 0 & 5951.57 \\
\hline Ferry Terminal & 0.112 & 2.047 & 0 & 147.06 \\
\hline Marina & 0.95 & 60.98 & 0 & 32409.04 \\
\hline Public Sports Airport & 0.017 & 1.208 & 0 & 246.98 \\
\hline Airport & 0.056 & 0.4 & 0.001 & 73.99 \\
\hline Business Facility & 7.75 & 874.430 & 0 & 119087.95 \\
\hline Grocery Store & 2633.29 & 20791.47 & 0.136 & 1150218.5 \\
\hline Automobile Dealership & 566.41 & 22283.53 & 0.068 & 6990278 \\
\hline Petrol/Gasoline Station & 1170.9 & 149006.53 & 0.089 & 22218256 \\
\hline Motorcycle Dealership & 2.17 & 63.59 & 0 & 6241.81 \\
\hline Restaurant & 13752.84 & 183004.14 & 0.158 & 7465020 \\
\hline Nightlife & 331.04 & 4674.83 & 0.011 & 252470.58 \\
\hline Historical Monument & 82.06 & 898.55 & 0.009 & 165075.89 \\
\hline Bank & 19111.94 & 731589.94 & 0.107 & 36176196 \\
\hline Shopping & 33.98 & 944.29 & 0.003 & 59529.23 \\
\hline Hotel & 395.59 & 18001 & 0.079 & 5502869 \\
\hline Ski Resort & 0.001 & 0.011 & 0 & 3.79 \\
\hline Other Accommodation & 0 & 0.001 & 0 & 0.035 \\
\hline Tourist Information & 9.46 & 226.83 & 0 & 13717.95 \\
\hline Rental Car Agency & 44.97 & 2841.45 & 0.003 & 779683.25 \\
\hline Parking Lot & 28.91 & 430.06 & 0.019 & 115492.81 \\
\hline Parking Garage/House & 742.8 & 9348.26 & 0.002 & 400110.72 \\
\hline Park and Ride & 0.07 & 2.14 & 0 & 158.94 \\
\hline Auto Service and Maintenance & 396.06 & 12310.41 & 0.049 & 2346258.25 \\
\hline Cinema & 48.434 & 624.53 & 0.001 & 42780.5 \\
\hline Rest Area & 0.08 & 0.288 & 0 & 92.403 \\
\hline Performing Arts & 73.62 & 1116.37 & 0.001 & 54141.12 \\
\hline Bowling Center & 1.51 & 35.14 & 0 & 1407.18 \\
\hline
\end{tabular}




\begin{tabular}{lrrrr} 
Sports Complex & 16.66 & 710.71 & 0.001 & 59071.56 \\
Park/Recreation Area & 86.49 & 2055.71 & 0.013 & 170288.89 \\
Casino & 1.81 & 117.86 & 0 & 98100.57 \\
Convention/Exhibition Center & 1.46 & 34.34 & 0 & 3156.54 \\
Golf Course & 0.23 & 14.33 & 0.002 & 6709.77 \\
Civic/Community Center & 34.43 & 657.57 & 0.001 & 32317.98 \\
Amusement Park & 0.06 & 0.944 & 0 & 372.68 \\
Sports Center & 90.89 & 1404.67 & 0.007 & 151129.45 \\
Ice Skating Rink & 1.04 & 38.4 & 0 & 1974.128 \\
Tourist Attraction & 52.47 & 37035.47 & 0.016 & 36589404 \\
Hospital & 6.67 & 86.66 & 0.001 & 11558.17 \\
Higher Education & 6.16 & 142.41 & 0 & 11387.38 \\
School & 604.17 & 10026.69 & 0.019 & 1833594.75 \\
Library & 4.084 & 101.641 & 0 & 13151.497 \\
Museum & 90.35 & 2739.27 & 0.001 & 184048.77 \\
City Hall & 10.01 & 217.63 & 0.001 & 19628.19 \\
Police Station & 40.37 & 689.65 & 0.006 & 52615.81 \\
Post Office & 744.69 & 32630.13 & 0.003 & 1611744.75 \\
Department Store & 3.87 & 63.6 & 0 & 4109.3 \\
Home Specialty Store & 0.035 & 0.18 & 0 & 11.24 \\
Pharmacy & 2462.58 & 19605.72 & 0.06 & 2035483.87 \\
Specialty Store & 0.86 & 30.17 & 0 & 1693.24 \\
Sporting Goods Store & 0.75 & 29.79 & 0 & 3916.87 \\
Medical Service & 16.98 & 497.05 & 0.001 & 30171.51 \\
Consumer Electronics Store & 5.088 & 66.25 & 0 & 16685.24 \\
Industrial Zone & 6.77 & 222.89 & 0.018 & 68646.44 \\
Place of Worship & 207.04 & 1114.24 & 0.003 & 102681.3 \\
Embassy & 196.004 & 3601 & 0.006 & 365454.06 \\
Book Store & 371.41 & 11131.42 & 0 & 648498.06 \\
\hline \hline & & & & \\
& & & & 0 \\
& & & &
\end{tabular}

Source: own elaboration on data from INE (2009), INE (2005) and ESRI (2009). Neighborhoods are squares with sides measuring 0.005 degrees. Averages are 2001-population weighted. Gravities scaled at $10^{6}$. 
Table 3: Native Outflows in response to Immigrant Inflows: 2001-2008

\begin{tabular}{|c|c|c|c|c|c|c|}
\hline \multirow{3}{*}{$\begin{array}{l}\text { Dependent variable } \\
\text { Method }\end{array}$} & \multicolumn{6}{|c|}{ Local Change in the Native Population: $\Delta n a t_{k, m, 2001 \_2008}$} \\
\hline & \multicolumn{4}{|c|}{ OLS } & \multicolumn{2}{|c|}{ 2SLS } \\
\hline & (1) & (2) & (3) & (4) & $(5)$ & (6) \\
\hline Developing-country migrants: $\Delta i m_{k, m, 2001 \_2008}^{D G}$ & $\begin{array}{c}-0.708^{* * *} \\
(0.030)\end{array}$ & $\begin{array}{c}-0.315^{* * *} \\
(0.061)\end{array}$ & $\begin{array}{c}-0.363^{* * *} \\
(0.053)\end{array}$ & & $\begin{array}{c}-0.454^{* * *} \\
(0.078)\end{array}$ & $\begin{array}{c}-0.327^{* * *} \\
(0.068)\end{array}$ \\
\hline Developed-country migrants: $\Delta i m_{k, m, 2001 \_2008}^{D D}$ & $\begin{array}{c}1.375^{* * *} \\
(0.211)\end{array}$ & $\begin{array}{c}1.135^{* * *} \\
(0.218)\end{array}$ & $\begin{array}{c}1.587^{* * *} \\
(0.274)\end{array}$ & $\begin{array}{c}1.574^{* * *} \\
(0.277)\end{array}$ & $\begin{array}{c}1.329^{* * *} \\
(0.470)\end{array}$ & \\
\hline Eastern Europe & & & & $-0.320(0.093)^{* * *}$ & & \\
\hline Latin America & & & & $-0.340(0.104)^{* * *}$ & & \\
\hline Subsaharian Africa & & & & $-0.831(0.318)^{* * *}$ & & \\
\hline Maghreb & & & & $0.211(0.237)$ & & \\
\hline Rest of Asia & & & & $-0.665(0.145)^{* * *}$ & & \\
\hline Observations & 28,523 & 28,523 & 22,043 & 22,043 & 22,043 & 22,043 \\
\hline Adj.R-squared (OLS) / Kleibergen-Paap F (IV) & 0.311 & 0.509 & 0.555 & 0.558 & 148.813 & 842.955 \\
\hline$\sum_{i=1}^{4} \kappa_{i} p o p_{k, m, t-1}^{i}$, Metro FE, and Controls & No & Yes & Yes & Yes & Yes & Yes \\
\hline Trimmed Sample & No & No & Yes & Yes & Yes & Yes \\
\hline
\end{tabular}

Source: own elaboration on data described in Table 2. Robust standard errors in parentheses. ***: significant at 1\%; **: significant at 5\%; *: significant at $10 \%$. Each observation represents a geographical quadrant and is weighted by its initial population. All regressions include metropolitan area fixed effects. $f\left(p_{0} p_{k, m, 2001}\right)$ refers to a quartic polynomial in $p o p_{k, m, 2001}$. In columns $3-6$, The sample has been trimmed by droping 1 percent of the population in, respectively, the quadrants with lowest and highest population growth. 
Table 4: Immigrants and Native Outflows: Heterogeneity and Supply (2SLS)

\begin{tabular}{|c|c|c|c|c|c|c|c|c|}
\hline \multirow[t]{2}{*}{ Dependent Variable } & \multicolumn{3}{|c|}{$\Delta n_{a} t_{k, m, 2001 \_2008}$} & \multicolumn{3}{|c|}{$\Delta$ Buildings $s_{k, m, 2001 \_2008}$} & \multicolumn{2}{|c|}{$\Delta n a t_{k, m, 2001 \_2008}$} \\
\hline & $(1)$ & $(2)$ & $(3)$ & $(4)$ & $(5)$ & (6) & $(7)$ & (8) \\
\hline Developing-country inmigrants: & -0.040 & $-0.426^{* * *}$ & & $0.564^{* * *}$ & $0.641^{* * *}$ & $0.993^{*}$ & $-0.297^{* * *}$ & 0.142 \\
\hline$\Delta i m_{k, m, 2001 \_2008}^{D G}$ & $(0.188)$ & $(0.101)$ & & $(0.156)$ & $(0.179)$ & $(0.508)$ & $(0.076)$ & $(0.215)$ \\
\hline Latin American & & & $\begin{array}{l}-0.137 \\
(0.166)\end{array}$ & & & & & \\
\hline Other Developing & & & $\begin{array}{c}-0.451^{* * *} \\
(0.082)\end{array}$ & & & & & \\
\hline Observations & 5,160 & 15,479 & 22,043 & 22,043 & 5,509 & 16,534 & 5,509 & 16,534 \\
\hline Sample & Hi-ed & Low-ed & All & All & Densest & Rest & Densest & Rest \\
\hline
\end{tabular}

Source: own elaboration on data described in Table 2. Robust standard errors in parentheses. ${ }^{* * *}$ : significant at $1 \%$; ${ }^{* *}$ : significant at $5 \%$; *: significant at $10 \%$. Each observation represents a geographical quadrant and is weighted by its initial population. All regressions include metropolitan area fixed effects and all controls in Table 3 column 3. The sample has been trimmed by droping 1 percent of the population in, respectively, the quadrants with lowest and highest population growth. 
Figure 1: Evolution of the foreign-born population share

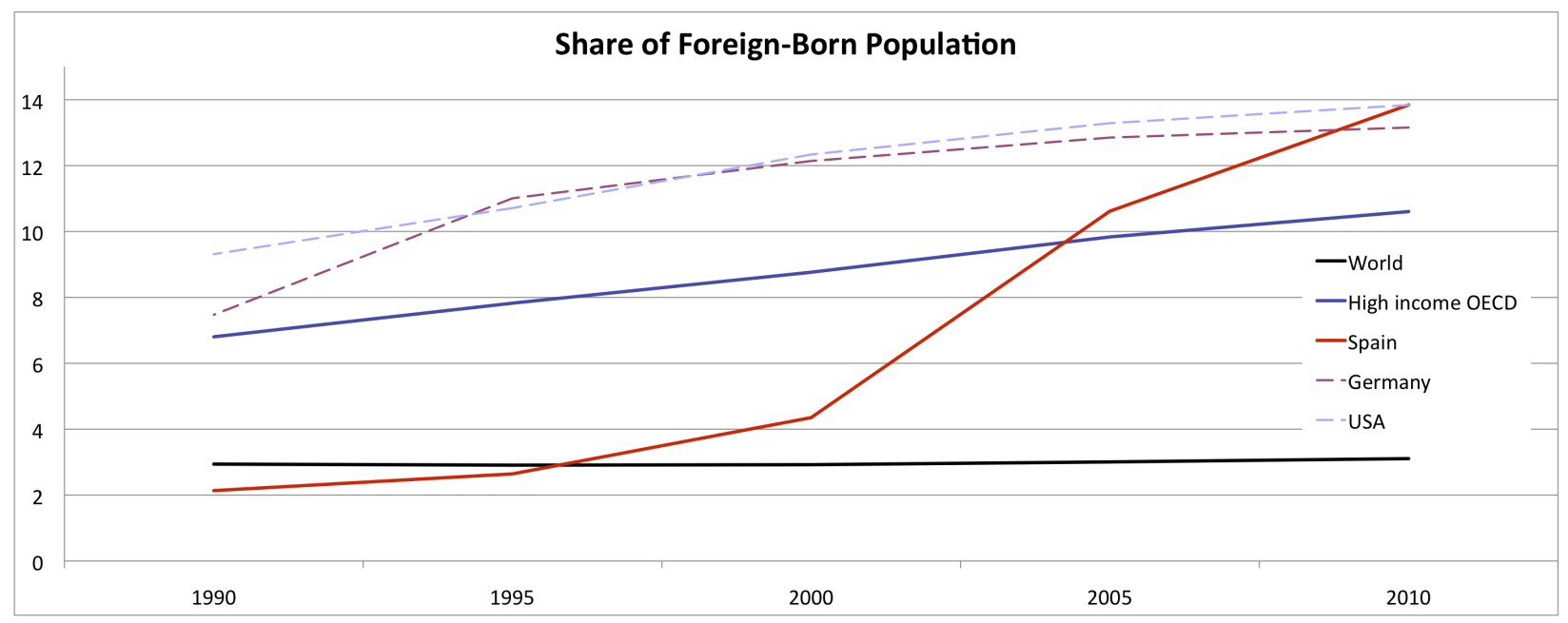

Source: own elaboration on data from World Bank (2013) 
Figure 2: Distribution of the share of immigrants by province in 2001 and 2008
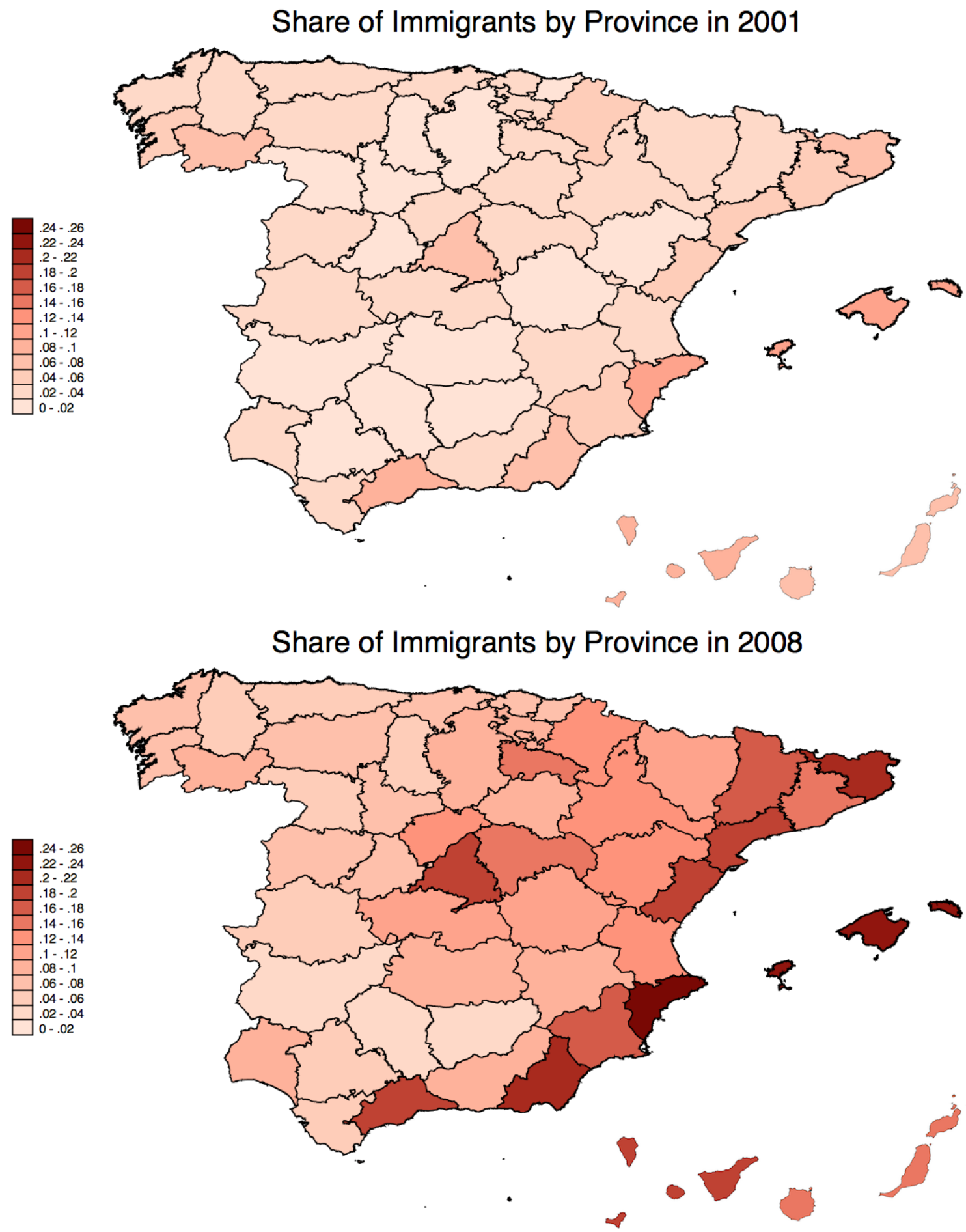

Source: own elaboration on data from INE (2009) 
Figure 3: Comparing segregation levels in Spain and the US

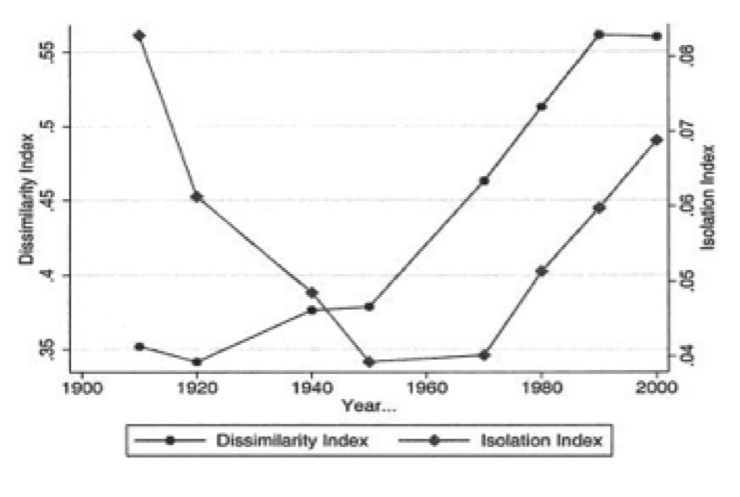

us

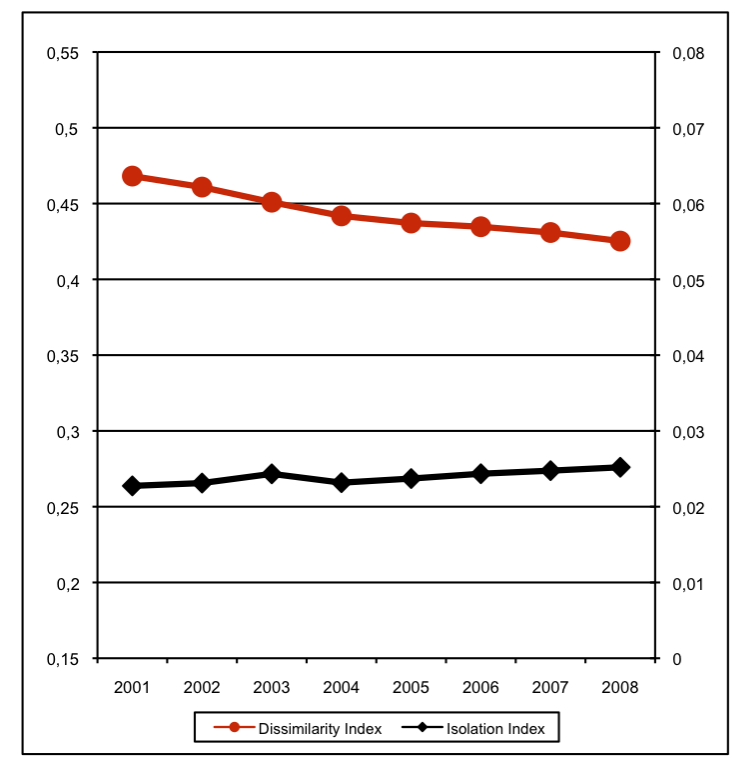

SPAIN

Source: Cutler, Glaeser, and Vigdor (2008) and own elaboration on data from INE (2009). In the Spanish case, neighborhoods are 2008 censal sections taken back in time using our geocoded addresses. Indexes calculated averaging immigrant communities with at least 1,000 inhabitants in a metro area, weighted by the size of the community in each metro area. 
Figure 4: LATE of Neighborhood Ethnic Change Parameters

\section{$\mathrm{T}=\mathbf{0}$}

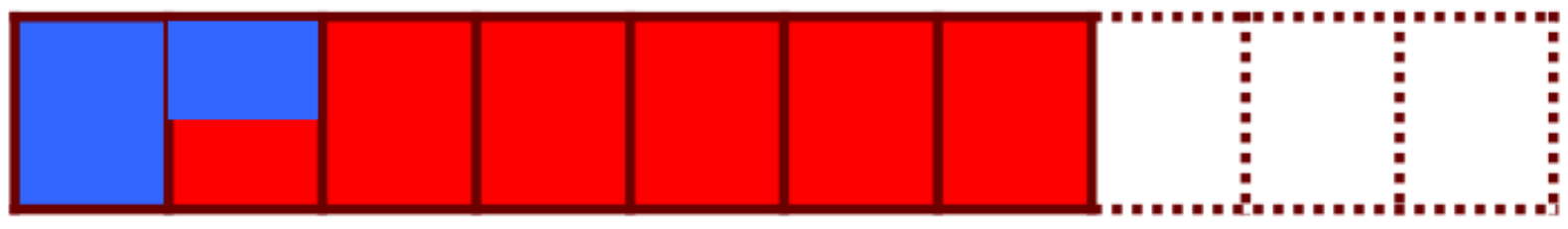

\begin{tabular}{|c|c|c|c|c|c|c|c|c|c|}
\hline $\begin{array}{c}N=1 \\
P o p=100\end{array}$ & $\begin{array}{c}N=2 \\
P o p=100\end{array}$ & $\begin{array}{c}N=3 \\
P o p=100\end{array}$ & $\begin{array}{c}N=4 \\
P o p=100\end{array}$ & $\begin{array}{c}N=5 \\
P o p=100\end{array}$ & $\begin{array}{c}N=6 \\
P o p=100\end{array}$ & $\begin{array}{c}N=7 \\
P o p=100\end{array}$ & $\begin{array}{c}N=8 \\
P o p=0\end{array}$ & $\begin{array}{c}N=9 \\
P o p=0\end{array}$ & $\begin{array}{c}N=10 \\
P o p=0\end{array}$ \\
\hline
\end{tabular}

\section{$\mathrm{T}=10$}

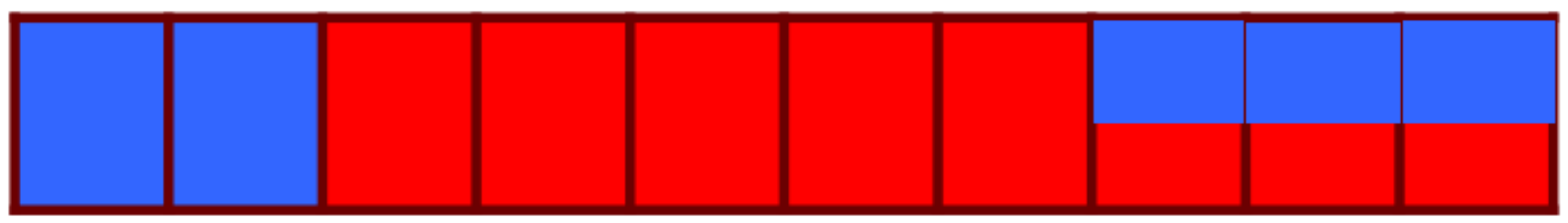

\begin{tabular}{|c|c|c|c|c|c|c|c|c|c|}
$\begin{array}{c}N=1 \\
P o p=100\end{array}$ & $\begin{array}{c}N=2 \\
P o p=100\end{array}$ & $\begin{array}{c}N=3 \\
P o p=100\end{array}$ & $\begin{array}{c}N=4 \\
P o p=100\end{array}$ & $\begin{array}{c}N=5 \\
P o p=100\end{array}$ & $\begin{array}{c}N=6 \\
P o p=100\end{array}$ & $\begin{array}{c}N=7 \\
P o p=100\end{array}$ & $\begin{array}{c}N=8 \\
P o p=100\end{array}$ & $\begin{array}{c}N=9 \\
P o p=100\end{array}$ & $\begin{array}{c}N=10 \\
P o p=100\end{array}$ \\
\hline
\end{tabular}

The figure illustrates a hypothetical city with 10 neighborhoods depicted as contiguous rectangles. Eight of the neighborhoods are populated at $\mathrm{T}=0$, whereas 3 new neighborhoods are only developed subsequently at $\mathrm{T}=1$. The share of immigrant ethnic minorities (majorities) in each neighborhood is signified by the area in in blue (red). By assumption, tipping dynamics are present in the older established neighborhood $(\mathrm{N}=2)$, which have crossed the tipping threshold at $\mathrm{T}=0$. However, newly developed neighborhoods are seeing considerable ethnic mixing. In this example, empirical methods that use past settlement patterns to estimate future ethnic majority flows provide a local average treatment effect (LATE) that is starker than the global average treatment effect. 
Figure 5: Local average smooth plot of adjusted native inflows (2001-2008) by initial share of immigrants (2001)

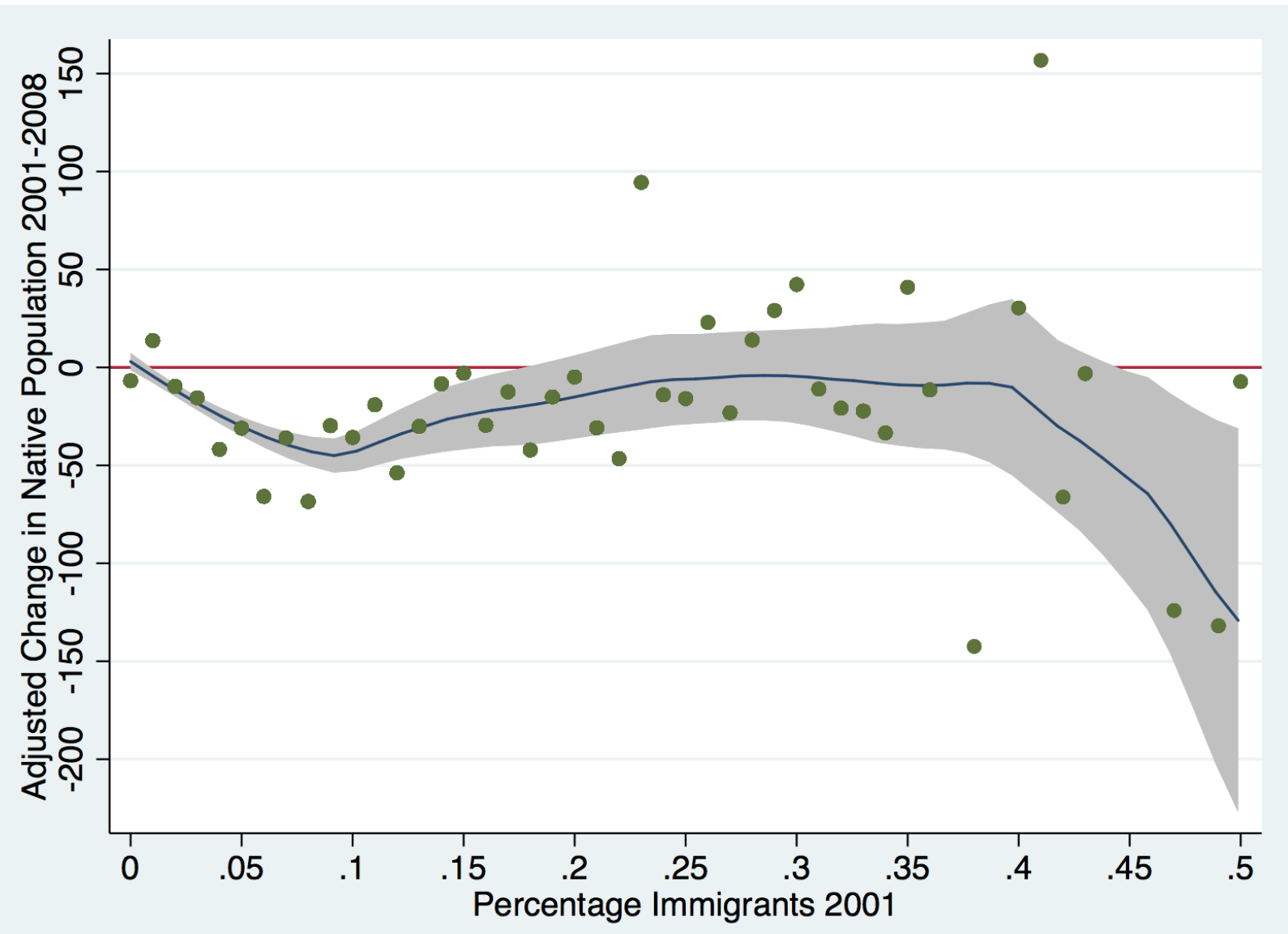

The graph uses information on all neighborhoods that were populated in 2001. It uses the Epanechnikov kernel to smooth local means of adjusted native inflows by group of neighborhoods sorted according to their initial immigrant concentration. Native inflows are adjusted by estimating a regression on all variables in table 3 and adding the residuals to the prediction corresponding to the national average neighborhood characteristics. 
Figure 6: Neighborhoods with positive native growth and with above average migrant growth in Madrid metro area (2001-2008)
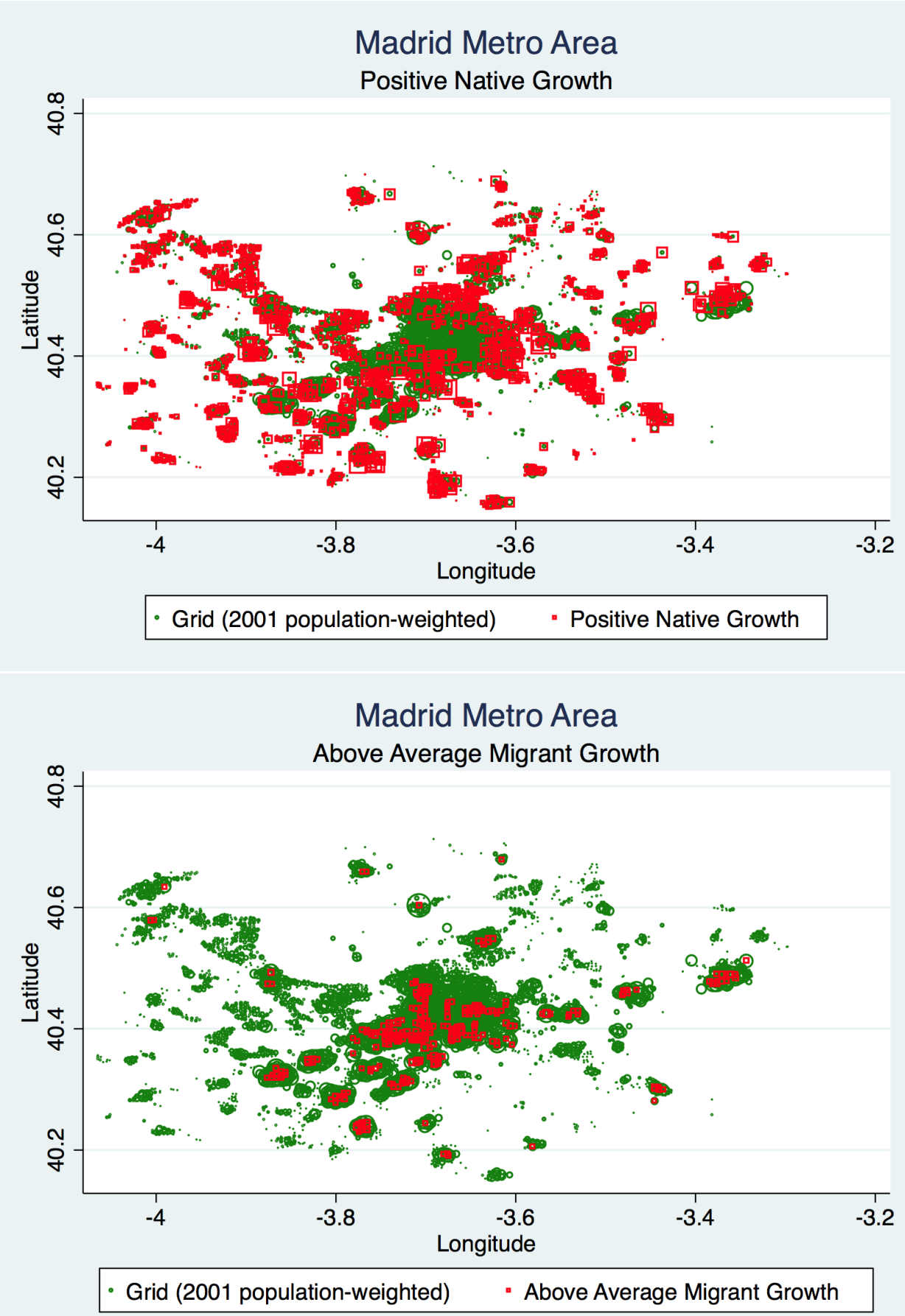

Source: own elaboration on data from INE (2009). Circles proportional to population in 2001. Squares proportional to 2001-2008 changes. 
Figure 7: Neighborhoods with positive native growth and with above average migrant growth in Barcelona metro area (2001-2008)
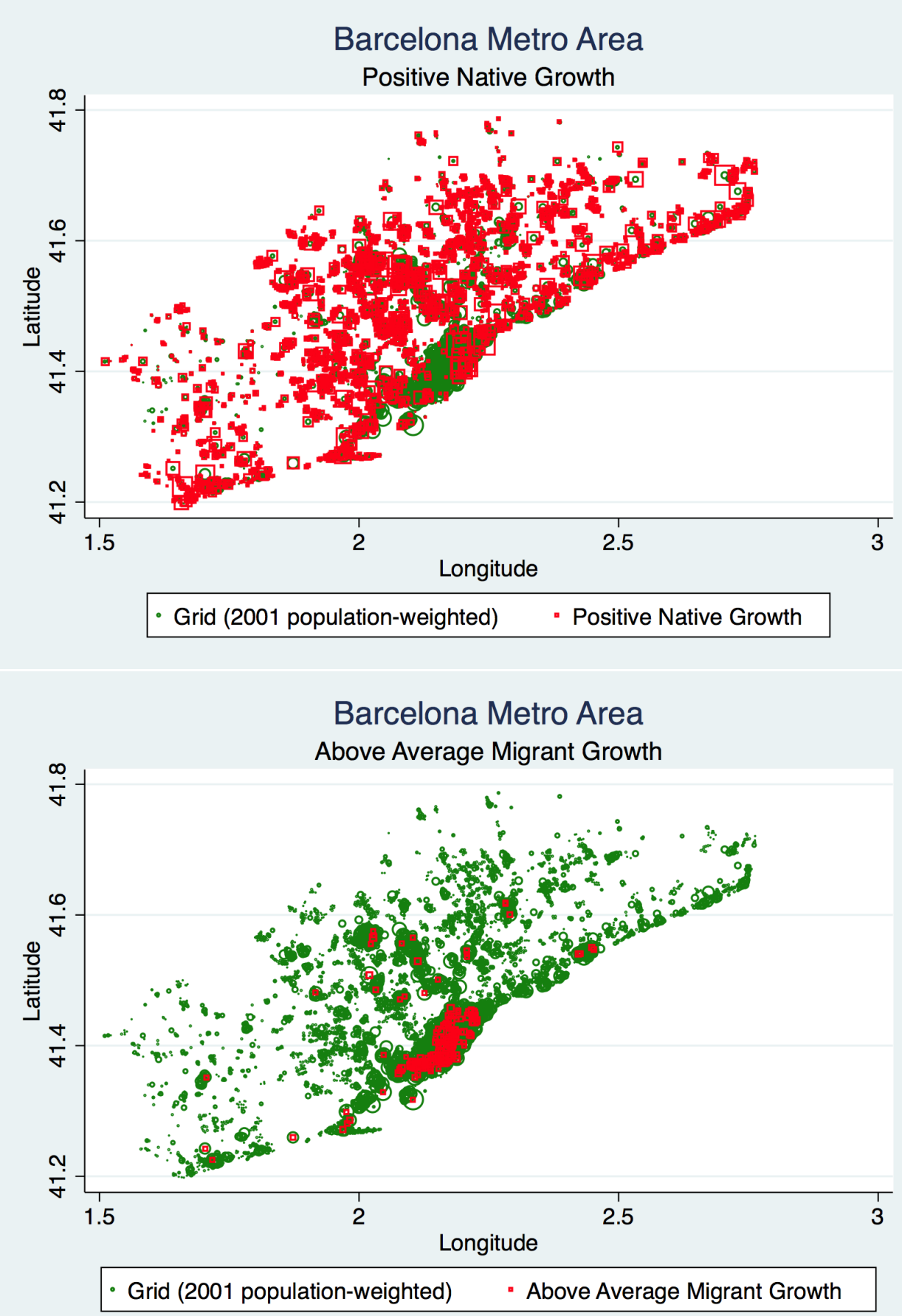

Source: own elaboration on data from INE (2009). Circles proportional to population in 2001. Squares proportional to 2001-2008 changes. 
Figure 8: Local average smooth plots of native and developing-country immigrant inflows in each quadrant by distance to city center

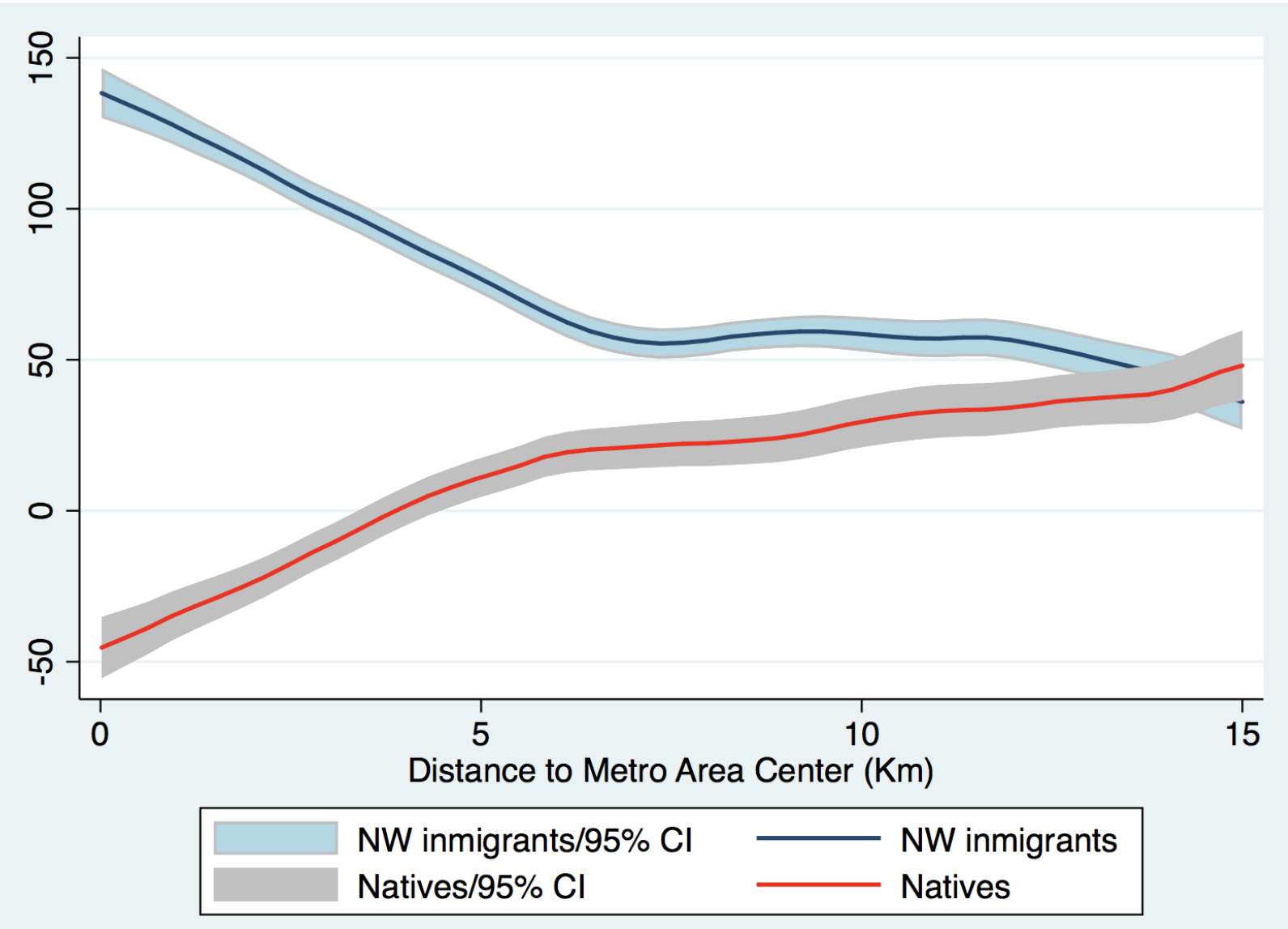


Figure 9: Collocation of Natives and Inmigrants in New Neighborhoods

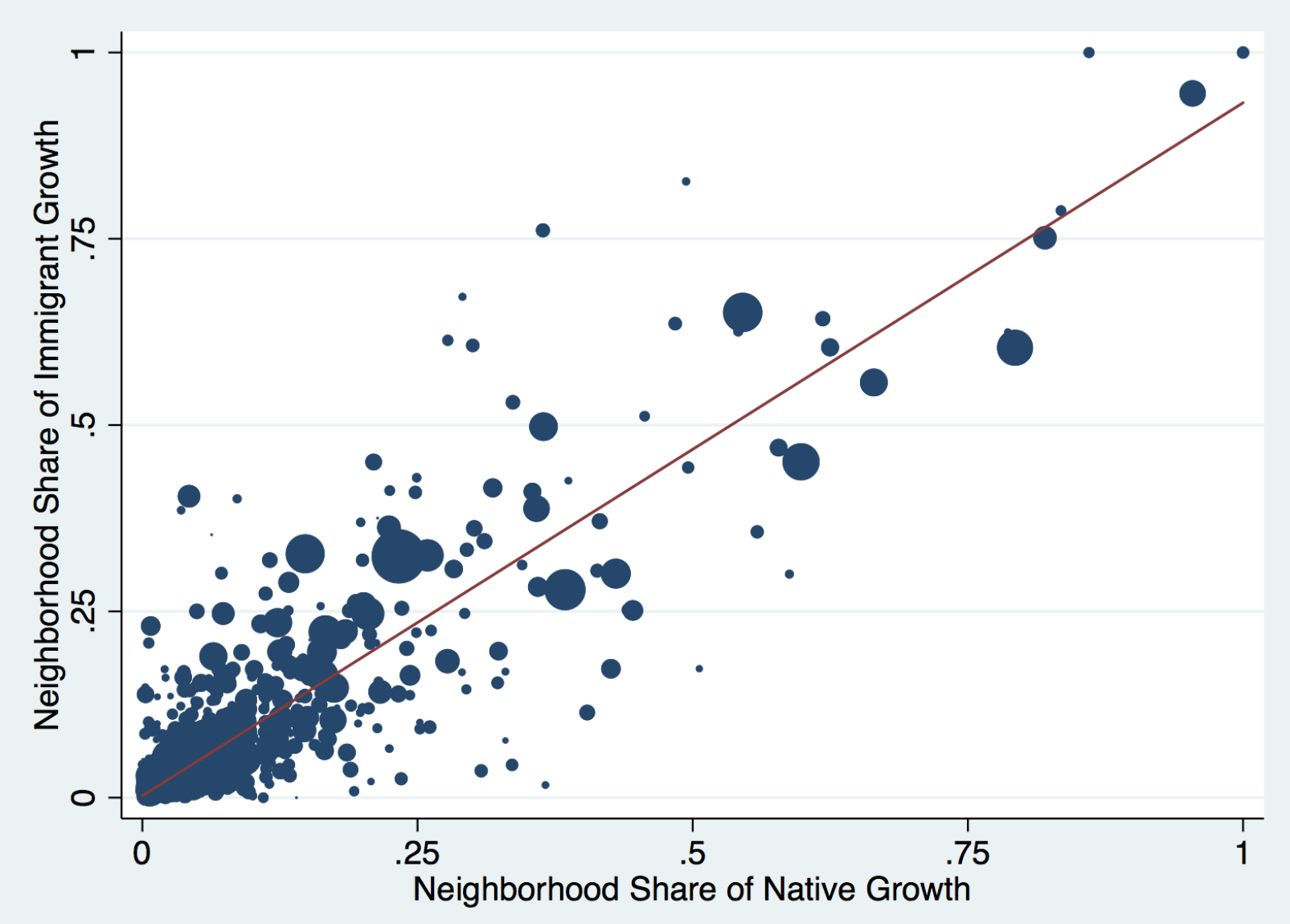




\section{Appendices}

\section{A Construction of the dataset}

\section{A.1 Sample selection}

We start from 28,870 grid squares matched between 2001 and 2008 in the metro areas defined by Ministerio de Vivienda (2007) at the municipality level. We next drop 13 squares where only one individual was registered and he/she was aged less than 15 in 2001 (6 cases) or 2008 ( 7 cases). This leads us to 28,857 observations. 328 of them have been identified as having address geocoding problems either in 2001 or in 2008. This amounts to 0.6 percent of the relevant population in 2001. The most problematic squares are Tenerife (10 percent) and Tarragona-Reus (5 percent). We are left with 28,529 valid observations. We still drop for our analysis 6 neighborhoods that are outliers either in terms of implausible native population decline (2 neighborhoods that lost more than 8,000 natives between 2001-2008) or in terms of the predicted growth from the instrument (2 neighborhoods predicted to get more than 4,000 developing-country immigrants into them and 2 neighborhoods predicted to get more than 8,000 developing-country immigrants). These outliers do not affect the results but some graphical representations in the paper worsen when they are included. Outliers contained overall 54,816 inhabitants in 2001 and 61,438 in 2008 (only 0.20 percent of the relevant population). After these operations, we are left with our main sample of 28,523 observations (Table 3, column 1).

\section{A.2 2001 Census Indices}

The 2001 Spanish Census (INE, 2005) provides us with a set of variables referred to each of 34,251 censal sections in Spain. Censal sections are administrative divisions for electoral purposes and are supposed to have between 500 and 2,500 inhabitants. In 2001, their average population was 1,193 (s.d.=590). 94 percent of them had the correct size.

We assign each of our addresses to the 291 average characteristics of its censal section in 2001. The included variables and their descriptives are shown in Table 2. Most variables are self-explanatory except for the four summary indices that we calculate. These indices are the results of two principal component analysis on several variables. 
- The first one uses the following Census variables: share of employed individuals in the neighborhood commuting by car alone, by car with passengers, by bus, by subway, by train, by motorcycle, by bike or on foot, share of population owning one car, two cars or three or more. We take the first two principal components weighted by 2001 population. The first accumulates 55 percent of the variance and we call it the car use index. The second gathers 16 percent of the variance and we call it the pedestrian index.

- The second one uses the following Census variables: share of population with public water, private water, sanitation services, gateway services, aspect of the building (scored by the interviewer), gas services, phone, hot water, heating, air conditioner, height of the building, elevator, noise level, contamination, crime, green areas and dirtiness. Different categories of these variables are included to total 42 variables. Again, we take the two principal components weighted by 2001 population. The first accumulates 38 percent of the variance and we call it the building height index. The second gathers 13 percent of the variance and we call it the neighborhood quality index.

\section{A.3 2008 Gravities}

We geocoded our Padrón (INE, 2009) data by matching each address with addresses from ESRI StreetMap Premium Europe NAVTEQ 2009 Release 2 (ESRI, 2009). We end up with 7,568,601 uniquely identified addresses. For each address, we calculated its distance in meters to a series of 62 features (points of interest) from the map server, such as hospitals, exit roads, schools, bus stops, metro stops, etc. In the end, for each address, we have six different measures of amenities for each of the 62 points of interest. The first measure is the minimum distance between each address and each of the points of interest. The other five measures are gravities: sums of points of interest in Spain weighted by distance. That is:

$$
g_{i}^{p, \alpha}=\sum_{n_{p}=1}^{N_{p}} d_{i, n_{p}}^{-\alpha}
$$

where $i$ is an address, $p$ is a point of interest (i.e. hospitals), $N_{p}$ is the number of points of interest $p$ in the radius where $i$ is located, $\alpha$ is a coefficient that takes values $\{0.5 ; 1 ; 2 ; 3$; 4) and $d_{i, n_{p}}$ is the distance between address $i$ and point of interest $n_{p}$ (i.e. one particular hospital). 
Table 2 shows summary statistics for gravities calculated for $\alpha=2$. They have been multiplied by $1,000,000$ to make the numbers visible.

\section{B Robustness to Quadrants with 0.01 Degree Sides. Results at the Municipal and Metro Level}

In this section we reproduce the results in tables 3 and 4 using quadrants of side 0.01 latitude and longitude degrees. This corresponds approximately to a side of length 1.1 kilometers.

Table B1 shows results mimicking the specifications in table 3. Note that, while a theoret-

ical rectangle contains four smaller rectangles with half its side, the number of observations amount to only 43 percent of the equivalent in Table 3. This is so because many of the smaller 0.005 quadrants had to be dropped due to lack of any population living there both in 2001 and 2008. Generally speaking, the displacement effects using larger quadrants hovers around -0.2 , which is smaller than in Table 3. Findings are consistent with the idea that very local displacement is due to mechanical housing market effects: one third of the natives counter-factually displaced from the smaller quadrants could be simply relocating into extremely-proximate areas. However, we cannot reject equality between the coefficients in tables 3 and B1. In contrast to the coefficient on immigrants from developing countries, as discussed in the text, the results arising from instrumenting for the developed-country inflows-in column (5)-are rather unstable.

In Table B2 we mimic the specifications of Table 4. Results are similar, following the same patterns as in the main regressions.

In Table B3 we present results of regressions with the change in the native population by municipality (columns 1,2, and 3) or metropolitan area on the left-hand side. Regressions include a quadratic in initial population and average municipal/metro values for a subset of other controls in Table 3 column 3, exclusive of neighborhood characteristics and POI gravities. We instrument immigrant arrivals using national growth by nationality interacted with their initial municipal or metro location. Municipal regressions include metropolitan fixed effects. Column 1 show results using the full municipality sample with population weights, implying a displacement effect of about -0.2. However, the results are quite sensitive to the dynamics in the largest municipalities. Dropping Madrid and Barcelona already decreases the coefficient by about one-third (column 2). Results become insignificant when 
we are not to weight by initial population (column 3). This is in contrast to our main coefficients in table 3, which are robust to the exclusion of Madrid and Barcelona, or to the omission of population weights. Municipal results suggest that, in line with previous evidence, there was a modest displacement effect from the largest cities, which saw more suburbanization. In most other areas of the country, immigrants displaced natives from neighborhoods, but natives tended to relocate within the same municipalities.

All results in the paper include metro fixed effects, and thus have to be interpreted in terms of population flows within metropolitan areas. In column 4 of Table B1 we examine flows across metro areas, finding a positive association between immigrant arrivals and native growth. The results are very similar to those in Fernández-Huertas Moraga, Ferrer, and Saiz (2011), who study population flows across the 52 Spanish provinces and independent cities. 
Table B1: Immigrants and Native Inflows: 2001-2008: Table 3 with Larger 0.01 degree Quadrants

\begin{tabular}{|c|c|c|c|c|c|c|}
\hline \multirow{3}{*}{$\begin{array}{l}\text { Dependent variable } \\
\text { Method }\end{array}$} & \multicolumn{6}{|c|}{ Local Change in the Native Population: $\Delta n a t_{k, m, 2001 \_2008}$} \\
\hline & \multicolumn{4}{|c|}{ OLS } & \multicolumn{2}{|c|}{ 2SLS } \\
\hline & $(1)$ & $(2)$ & $(3)$ & $(4)$ & $(5)$ & $(6)$ \\
\hline Developing-country migrants: $\Delta i m_{k, m, 2001 \_2008}^{D G}$ & $\begin{array}{c}-0.851^{* * *} \\
(0.037)\end{array}$ & $\begin{array}{c}-0.213^{* * *} \\
(0.042)\end{array}$ & $\begin{array}{c}-0.232^{* * *} \\
(0.041)\end{array}$ & & $\begin{array}{c}-0.221^{* * *} \\
(0.077)\end{array}$ & $\begin{array}{c}-0.199^{* *} \\
(0.080)\end{array}$ \\
\hline Developed-country migrants: $\Delta i m_{k, m, 2001 \_2008}^{D D}$ & $\begin{array}{c}0.745^{* * *} \\
(0.214)\end{array}$ & $\begin{array}{c}1.108^{* * *} \\
(0.200)\end{array}$ & $\begin{array}{c}1.344^{* * *} \\
(0.237)\end{array}$ & $\begin{array}{l}1.358^{* * *} \\
(0.238)\end{array}$ & $\begin{array}{c}0.323 \\
(0.450)\end{array}$ & \\
\hline Eastern Europe & & & & $-0.127(0.085)$ & & \\
\hline Latin America & & & & $-0.082(0.075)$ & & \\
\hline Subsaharian Africa & & & & $-0.917(0.301)^{* * *}$ & & \\
\hline Maghreb & & & & $-0.153(0.212)$ & & \\
\hline Rest of Asia & & & & $-0.844(0.193)^{* * *}$ & & \\
\hline Observations & 12,465 & 12,465 & 10,012 & 10,012 & 10,012 & 10,012 \\
\hline Adj.R-squared (OLS) / Kleibergen-Paap F (IV) & 0.488 & 0.764 & 0.774 & 0.779 & 104.527 & 440.780 \\
\hline$\sum_{i=1}^{4} \kappa_{i} p o p_{k, m, t-1}^{i}$, Metro FE, and Controls & No & Yes & Yes & Yes & Yes & Yes \\
\hline Trimmed Sample & No & No & Yes & Yes & Yes & Yes \\
\hline
\end{tabular}

Source: own elaboration on data described in Table 2. Robust standard errors in parentheses. ***: significant at 1\%; **: significant at 5\%; *: significant at $10 \%$. Each observation represents a geographical quadrant and is weighted by its initial population. All regressions include metropolitan area fixed effects. $f\left(p o p_{k, m, 2001}\right)$ refers to a quartic polynomial in $p o p_{k, m, 2001}$. In columns $3-6$, The sample has been trimmed by dropping 1 percent of the population in, respectively, the quadrants with lowest and highest population growth. 
Table B2: Immigrants and Native Outflows: Table 4 with Larger 0.01 degree Quadrants

\begin{tabular}{|c|c|c|c|c|c|c|c|c|}
\hline \multirow[t]{2}{*}{ Dependent Variable } & \multicolumn{3}{|c|}{$\Delta n a t_{k, m, 2001 \_2008}$} & \multicolumn{3}{|c|}{$\Delta$ Buildings $s_{k, m, 2001 \_2008}$} & \multicolumn{2}{|c|}{$\Delta n a t_{k, m, 2001 \_2008}$} \\
\hline & $(1)$ & $(2)$ & $(3)$ & $(4)$ & $(5)$ & $(6)$ & $(7)$ & $(8)$ \\
\hline Developing-country inmigrants: & -0.065 & $-0.239 * *$ & & 0.390 & $0.453^{*}$ & $0.934^{* *}$ & $-0.187^{* *}$ & -0.053 \\
\hline$\Delta i m_{k, m, 2001 \_2008}^{D G}$ & $(0.158)$ & $(0.115)$ & & $(0.251)$ & $(0.233)$ & $(0.460)$ & $(0.086)$ & $(0.220)$ \\
\hline Latin American & & & $\begin{array}{c}0.221 \\
(0.219)\end{array}$ & & & & & \\
\hline Other Developing & & & $\begin{array}{c}-0.509 * * * \\
(0.117)\end{array}$ & & & & & \\
\hline Observations & 2,369 & 7,104 & 10,012 & 10,012 & 2,502 & 7,510 & 2,502 & 7,510 \\
\hline Sample & Hi-ed & Low-ed & All & All & Densest & Rest & Densest & Rest \\
\hline
\end{tabular}

Source: own elaboration on data described in Table 2. Robust standard errors in parentheses. ${ }^{* * *}$ : significant at $1 \%$; **: significant at $5 \%$; *: significant at $10 \%$. Each observation represents a geographical quadrant and is weighted by its initial population. All regressions include metropolitan area fixed effects and all controls in Table 3 column 3. The sample has been trimmed by droping 1 percent of the population in, respectively, the quadrants with lowest and highest population growth. 
Table B3: Immigrants and Native Outflows: Municipalities and Metro

\begin{tabular}{lccc|c}
\hline Dependent Variable & \multicolumn{3}{c}{$\Delta$ Mut $_{k, m, 2001 \_2008}$} \\
\hline & $(1)$ & $(2)$ & $(3)$ & $(4)$ \\
$\Delta i m_{k, m, 2001 \_2008}^{D G}$ & $-0.225^{* * *}$ & $-0.145^{* * *}$ & -0.068 & $0.235^{* *}$ \\
& $(0.043)$ & $(0.032)$ & $(0.051)$ & $(0.100)$ \\
Exclude MAD and BCN & No & Yes & Yes & No \\
Population Weights & Yes & Yes & No & Yes \\
Metro Area Fixed Effects & Yes & Yes & Yes & No \\
Observations & 742 & 740 & 740 & 83 \\
\hline
\end{tabular}

Source: own elaboration on data described in Table 2. Robust standard errors in parentheses. ***: significant at $1 \%$; **: significant at $5 \%$; : significant at $10 \%$. Each observation represents a municipality (1)-(3), or a metropolitan area (4). Observations weighted by their 2001 population, except in column (3). Regressions include a quadratic in initial population and average municipal/metro values for a subset of other controls in Table 3 column 3, exclusive of neighborhood characteristics and POI gravities. Regressions in columns (1)-(3) include metropolitan area fixed effects. 